\title{
Tropical thin cirrus and relative humidity observed by the Atmospheric Infrared Sounder
}

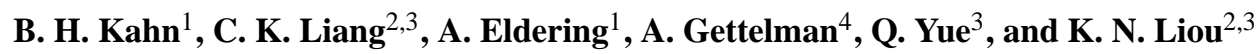 \\ ${ }^{1}$ Jet Propulsion Laboratory, California Inst. of Technology, Pasadena, CA, USA \\ ${ }^{2}$ Joint Inst. for Regional Earth System Science and Engineering, Univ. of California, Los Angeles, CA, USA \\ ${ }^{3}$ Dept. of Atmospheric and Oceanic Sciences, University of California, Los Angeles, CA, USA \\ ${ }^{4}$ National Center for Atmospheric Research, Boulder, CO, USA
}

Received: 30 October 2007 - Published in Atmos. Chem. Phys. Discuss.: 20 November 2007

Revised: 6 February 2008 - Accepted: 13 February 2008 - Published: 13 March 2008

\begin{abstract}
Global observations of cloud and humidity distributions in the upper troposphere within all geophysical conditions are critically important in order to monitor the present climate and to provide necessary data for validation of climate models to project future climate change. Towards this end, tropical oceanic distributions of thin cirrus optical depth $(\tau)$, effective diameter $\left(D_{e}\right)$, and relative humidity with respect to ice $\left(\mathrm{RH}_{\mathrm{i}}\right)$ within cirrus $\left(\mathrm{RH}_{\mathrm{ic}}\right)$ are simultaneously derived from the Atmospheric Infrared Sounder (AIRS). Corresponding increases in $D_{e}$ and cloud temperature are shown for cirrus with $\tau>0.25$ that demonstrate quantitative consistency to other surface-based, in situ and satellite retrievals. However, inferred cirrus properties are shown to be less certain for increasingly tenuous cirrus. In-cloud supersaturation is observed for $8-12 \%$ of thin cirrus and is several factors higher than all-sky conditions; even higher frequencies are shown for the coldest and thinnest cirrus. Spatial and temporal variations in $\mathrm{RH}_{\mathrm{ic}}$ correspond to cloud frequency while regional variability in $\mathrm{RH}_{\mathrm{ic}}$ is observed to be most prominent over the N. Indian Ocean basin. The largest cloud/clear sky $\mathrm{RH}_{\mathrm{i}}$ anomalies tend to occur in dry regions associated with vertical descent in the sub-tropics, while the smallest occur in moist ascending regions in the tropics. The characteristics of $\mathrm{RH}_{\mathrm{ic}}$ frequency distributions depend on $\tau$ and a peak frequency is located between $60-80 \%$ that illustrates $\mathrm{RH}_{\mathrm{ic}}$ is on average biased dry. The geometrical thickness of cirrus is typically less than the vertical resolution of AIRS temperature and specific humidity profiles and thus leads to the observed dry bias, shown with coincident cloud vertical structure obtained from the Cloud-Aerosol Lidar and Infrared Pathfinder Satellite Observation (CALIPSO). The
\end{abstract}

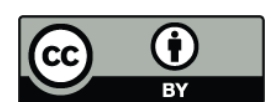

Correspondence to: B. H. Kahn (brian.h.kahn@jpl.nasa.gov) joint distributions of thin cirrus microphysics and humidity derived from AIRS provide unique and important regional and global-scale insights on upper tropospheric processes not available from surface, in situ, and other contemporary satellite observing platforms.

\section{Introduction}

Cirrus clouds are important regulators of climate (Ramanathan and Collins, 1991; Lynch et al., 2002) that cover $20-30 \%$ of the Earth and up to $70 \%$ of the tropics at any given time (Wylie and Menzel, 1999). They play important roles in stratospheric-tropospheric exchange and lower stratospheric dehydration (Holton et al., 1995), the upper tropospheric (UT) hydrological cycle (Baker, 1997), and in facilitating UT chemical processes (Popp et al., 2004).

Despite its tenuous nature, thin cirrus is an important contributor to the global radiation budget because of its large frequency of occurrence (Prabhakara et al., 1988), high altitude, low opacity, and small ice particles with instantaneous radiative forcing (McFarquhar et al., 2000; Comstock et al., 2002) significantly larger than the radiative effects of anthropogenic agents such as aerosols and changes in greenhouse gas concentrations (Forster et al., 2007). Geometrically and optically thin cirrus is most frequent within and below the tropical tropopause layer (TTL) and is generated and maintained to various degrees by convective detrainment (Lilly, 1988), in situ formation from mesoscale gravity waves (Kärcher and Ström, 2003), ascent associated with synoptic- and planetary-scale waves (Boehm and Verlinde, 2000; Jensen et al., 2001; Peter et al., 2003), and radiative cooling above cold convective anvils (Hartmann et al., 2001). By tracking cirrus evolution, Massie et al. (2002)

Published by Copernicus Publications on behalf of the European Geosciences Union. 
calculated that in situ and convective detrainment processes contribute approximately $50 \%$ each towards the observed cirrus frequency in the tropical UT. However, surface-based cloud radars at the Atmospheric Radiation Measurement (ARM) program tropical Pacific sites have further revealed regional and temporal variability in these estimates (Mace et al., 2006). Surface and space-based lidars demonstrate that convective and in situ generated cirrus have distinct altitude, spatial, microphysical, and optical characteristics. Cirrus formed in situ is geometrically and optically thinner, more laminar in appearance, is located at higher altitudes, and is composed of smaller ice particles compared to convectively generated cirrus (Winker and Trepte, 1998; Comstock et al., 2002). In the middle and high latitudes, baroclinic wave activity produces a majority of cirrus (Liou, 1986).

Cirrus cloud particles nucleate by either homogeneous freezing of soluble aerosol composed of aqueous solutions, heterogeneous nucleation from insoluble ice nuclei (IN) such as organics, mineral dust, and metals (DeMott et al., 2003), or a combination of both (e.g. Haag et al., 2003). Ice nucleation requires the ice saturation ratio $(S)$ to exceed a nominal value that depends on the water activity of the solute or the composition and nature of the IN. For homogeneous nucleation to occur, $S$ must typically exceed $1.4-1.7$ for water ice to spontaneously form (Koop et al., 2000). For heterogeneous nucleation to occur, $S$ is generally considered to be lower than that required for homogeneous nucleation. Some recent in situ observations of $S>1.7$ over a limited spatial and temporal extent (Jensen et al., 2005) suggest a possible role by organic coatings on aerosols in suppressing ice nucleation. Furthermore, recent laboratory measurements of low ice deposition coefficients may explain in part the existence of high $S$ within and adjacent to cold cirrus clouds composed of small ice particles (Magee et al., 2006). Observations of $S$ are also important for contrail formation, maintenance and impacts on cirrus frequency and microphysics (Minnis et al., 2004). Additionally, trends of increasing UT water vapor have been observed (Soden et al., 2005) and its relevance to climate sensitivity also suggests the importance of longterm monitoring of the UT. These and other studies demonstrate that the understanding of the UT hydrological cycle is far from complete (Peter et al., 2006). Therefore, improved measurements (greater precision, higher spatial and temporal sampling) of cirrus microphysics and humidity are critical to the investigation of the UT region.

A new generation of coordinated satellite platforms collectively known as the "A-train" is providing global observations of atmospheric temperature, water vapor, aerosol, cloud, surface, and trace gas properties with unprecedented capabilities (Stephens et al., 2002). For instance, UT cloud properties and relative humidity $(\mathrm{RH})$ are measured by the Atmospheric Infrared Sounder (AIRS), an infrared/microwave sounder on EOS Aqua that simultaneously observes cloudiness, temperature, and water vapor (Aumann et al., 2003). Using AIRS retrievals of temperature and spe- cific humidity, Gettelman et al. (2006) showed that ice supersaturation is frequent throughout the UT with latitudinal, regional and seasonal dependences. The frequency of supersaturation derived from AIRS is several times higher than observed by the Television Infrared Observation Satellite (TIROS) Operational Vertical Sounder (TOVS) (Gierens et al., 2004), attributable to improved spectral resolution, sensitivity, noise and calibration characteristics. Numerous recent studies have proven the utility of AIRS radiances for cloud detection, amount and height retrievals (Kahn et al., 2007a, b, 2008), and for the inference of cirrus optical depth $(\tau)$ and effective diameter $\left(D_{e}\right)$ (e.g. Kahn et al. 2003; Yue et al., 2007). Herein, simultaneous observations of thin cirrus $\tau$ and $D_{e}$ and in-cloud $\mathrm{RH}$ with respect to ice $\left(\mathrm{RH}_{\mathrm{ic}}\right)$ are derived from AIRS and their correlative relationships are quantified.

Previous studies emphasized the relationships between cirrus frequency and humidity. For instance, Sandor et al. (2000) and Clark (2005) used limb-viewing satellites to show that $\mathrm{UT}_{\mathrm{RH}}$ and cirrus frequency are positively correlated. Many in situ measurements of $\mathrm{RH}_{\mathrm{i}}$ within and adjacent to cirrus (e.g. Heymsfield et al., 1998; Ovarlez et al., 2002; Spichtinger et al., 2004; Jensen et al., 2005) and those derived from surface-based Raman lidar observations (Comstock et al., 2004) exist as well. They illustrate the high spatial and temporal detail of ice-supersaturated regions within cirrus, and in particular in situ instrumentation provides a more diverse and precise measurement capability over satellite observations though it is highly limited in spatial and temporal extent. Many parcel modeling studies of cirrus properties have shown that the evolution of $\mathrm{RH}_{\mathrm{ic}}$ is controlled to various extents by ice crystal number concentration, ice water content, size distribution, and other factors (e.g. Khvorostyanov et al., 2006; and references therein). Furthermore, Haag et al. (2003) has suggested that heterogeneous and homogeneous ice nucleation can be inferred from observed distributions of $\mathrm{RH}_{\mathrm{i}}$ originating within and adjacent to cirrus, although making this distinction from satellite observations has not been conclusively demonstrated to date. Therefore, AIRS retrievals of $\tau, D_{e}$, and in-cloud and adjacent clear sky $\mathrm{RH}_{\mathrm{i}}$ should be investigated for a sensitivity to cirrus formation and maintenance mechanisms, and to evaluate and improve the realism of climate model parameterizations of cirrus (e.g. Lohmann and Kärcher, 2002).

In this article, AIRS standard retrieval products and observed radiances are used to derive $\mathrm{RH}_{\mathrm{i}}, \tau$ and $D_{e}$ within tenuous cirrus over the tropical oceans. Section 2 discusses the cirrus retrieval approach, the required atmospheric and surface inputs and their error characteristics, and the propagation of the input errors through the cirrus radiative transfer model (RTM). The sensitivity of $\tau$ and $D_{e}$ to errors in RTM inputs is quantified for three representative thin cirrus cases. In Sect. 3, histograms and spatial distributions of cirrus quantities are shown and are then compared to distributions derived from other retrieval platforms. Furthermore, we 


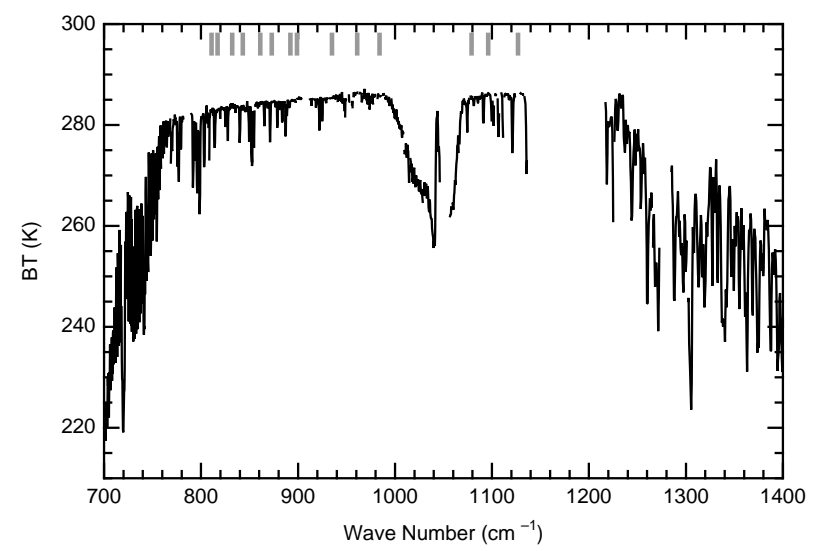

Fig. 1. Shown is an illustrative AIRS spectrum from granule number 11 on 10 April 2003 in the subtropical Southern Atlantic Ocean. The channels used for the cirrus retrievals are shown as vertical gray lines $(811,817,832,843,861,873,892,899,935,961,984,1079$, 1096 , and $\left.1127 \mathrm{~cm}^{-1}\right)$.

present joint histograms of $\tau, D_{e}$ and $\mathrm{RH}_{\mathrm{ic}}$, illustrate spatial distributions of $\mathrm{RH}_{\mathrm{i}}$ and in-cloud/clear sky $\mathrm{RH}_{\mathrm{i}}$ anomalies, and relationships between cirrus cloud geometrical thickness and $\mathrm{RH}_{\mathrm{ic}}$. In Sect. 4, the primary findings are summarized and potential applications of joint cirrus and humidity distributions are discussed.

\section{Methodology}

Here we provide a brief overview of the RTM and thin cirrus retrieval approach, the atmospheric and surface RTM inputs with a summary of uncertainties, and a quantification of the bias and variability in $\tau$ and $D_{e}$ caused by the various input uncertainties.

\subsection{Thin cirrus retrieval approach}

The inference of $\tau$ and $D_{e}$ employs a modified approach of Yue et al. (2007). A rapid, clear-sky RTM, the Optical Path Transmittance (OPTRAN) model (McMillin et al., 1995), is coupled to a thin cirrus parameterization. The simultaneous retrieval uses a minimization method that searches for the optimal fit between observed and simulated radiance spectra. A total of 14 channels are used in the $8-12 \mu \mathrm{m}$ window region (Fig. 1). Little to no sensitivity of $\tau$ and $D_{e}$ is observed in comparisons between simulations that use the channel list in Fig. 1 and the one used in Yue et al. (2007). This is consistent with studies of Moderate Resolution Imaging Spectroradiometer (MODIS) radiances that suggest little additional information content of cloud properties is available beyond a set of 4-5 channels (L'Ecuyer et al., 2006). Yue et al. (2007) define the ice crystal size and habit distributions as free parameters. In this work, the bulk cirrus scattering models developed by Baum et al. (2007) are used

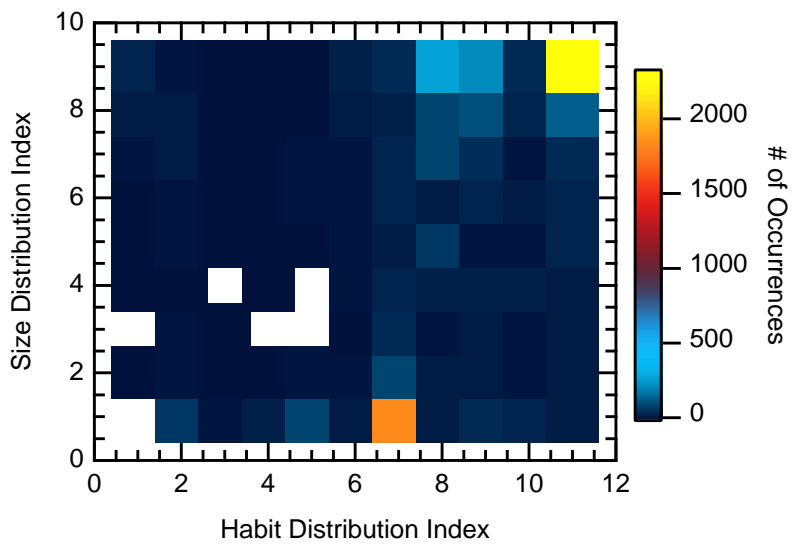

Fig. 2. Probability distribution for combinations of 9 size and 11 habit distributions used in Yue et al. (2007) applied to AIRS granule 139 on 1 July 2003 (13:54-14:00 UTC). There are three primary preferred combinations: the habit distribution described by McFarquhar et al. (1999) with $D_{e}=24 \mu \mathrm{m}$ (habit index=7, size index=1), $100 \%$ solid columns with $D_{e}=92 \mu \mathrm{m}$ (habit index $=11$, size index $=9$ ), and the size-dependent habit mixture of Baum et al. (2007) with $D_{e}=26 \mu \mathrm{m}$ (habit index=8, size index=9). The size distributions were obtained from the Central Equatorial Pacific Experiment (CEPEX); see Yue et al. (2007) for all size and habit distribution combinations.

for consistency with MODIS Collection 5 and to reduce the dimensionality of the retrieval parameter space for increased computational efficiency. Here $D_{e}$ is defined as $3 / 2$ times the ratio of the total volume to the total projected area following Eq. (4) in Baum et al. (2007) and cited references therein. To further justify the use of Baum et al. (2007), the frequency of the optimal fit for particular size and habit distribution combinations used in Yue et al. (2007) is shown for an illustrative AIRS granule in the tropics (Fig. 2). Three combinations occur most frequently: (1) the McFarquhar et al. (1999) habit distribution and $D_{e} \approx 24 \mu \mathrm{m}$ fit the thinnest cirrus best $(\tau \leq 0.3)$, (2) a $100 \%$ solid column distribution and $D_{e} \approx 92 \mu \mathrm{m}$ fit slightly thicker cirrus $(\tau \geq 0.4-0.5)$ more often, and (3) the size-dependent habit mixture of Baum et al. (2007) and $D_{e} \approx 26 \mu \mathrm{m}$ fit similar cirrus as in (2). In this work, we allow $D_{e}$ to be a free parameter and fix the habit mixture to that used in Baum et al. (2007). Although this simplifies the interpretation of $D_{e}$ and more readily facilitates a comparison to MODIS, other studies have demonstrated varying but significant impacts of ice crystal habit and size distributions on thermal IR radiances (Cooper et al., 2006; Wendisch et al., 2007; Yue et al., 2007) and is suggestive that the habit distribution may be a retrievable physical quantity in future retrieval efforts (Baran and Francis 2004).

For calculated clear sky radiance, temperature $T(z)$, specific humidity $q(z)$, and $\mathrm{O}_{3}(z)$ profiles are required along with surface temperature $\left(T_{S}\right)$, IR emissivity $(\varepsilon)$, IR reflectivity $(\rho)$, and the viewing geometry. AIRS Version 5 (V5) Level 2 (L2) Standard and Support products provide the 

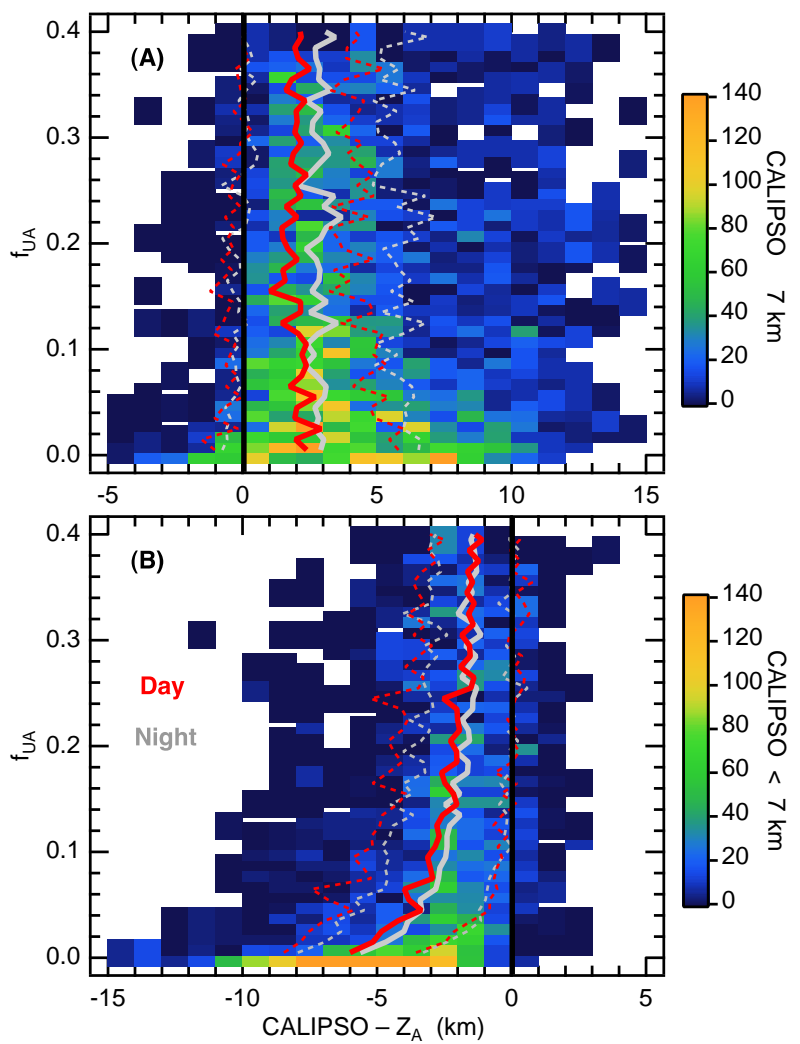

Fig. 3. CALIPSO-AIRS upper level cloud top height $\left(Z_{A}\right)$ as a function of effective cloud fraction $\left(f_{A}\right)$ for single-layered ( $f_{A}$ (upper) $>0$ and $f_{A}$ (lower) $=0$ ) clouds for $0<f_{A} \leq 0.4$. The CALIPSO height is defined to be the cloud top associated with the highest cloud feature using the $5 \mathrm{~km}$ feature mask. The bias $( \pm 1 \sigma$ variability) in CALIPSO-AIRS differences are the solid (dashed) lines. The daytime (nighttime) observations are shown in red (gray). (A) For subset of CALIPSO observations with cloud top height $\geq 7 \mathrm{~km}$. (B) same as (A) except for cloud top height $<7 \mathrm{~km}$.

RTM with these necessary inputs. For the cloudy radiance, the AIRS upper level cloud top temperature $\left(T_{C}\right)$ is used to detect and quantify the cloud height (Kahn et al., 2007a). The retrievals are limited to single-layers (according to AIRS) over the oceans with an effective cloud fraction $\left(f_{A}\right)$ of 0.02 $\leq f_{A} \leq 0.4$ and $T_{C} \leq 240 \mathrm{~K}$. The quantity $f_{A}$ is a product of cloud emissivity and cloud fraction within an AIRS FOV. Values less than 1.0 may arise from the presence of transmissive cloud or partial cloud coverage within the FOV (Kahn et al., 2007a, 2008). These limitations are imposed because (1) the parameterization is much less accurate above $\tau \geq 0.5-1.0$ or or $f_{A} \geq 0.3-0.4$ when scattering begins to dominate, (2) $T_{S}, \varepsilon$, and $\rho$ are less accurately characterized over land, (3) the retrieval in Yue et al. (2007) is only designed for singlelayered clouds, and (4) in lieu of a more precise phase assessment methodology, $T_{C} \leq 240 \mathrm{~K}$ very likely identifies the presence of ice clouds. Furthermore, the effects of cloud thickness are not included in the modified approach of Yue

et al. (2007) that is presented here. Hong et al. (2007) simulated MODIS IR bands to show that, for the types of thin cirrus investigated here, a low bias in $\tau$ up to $10 \%$ and likewise a high bias in $D_{e}$ up to $20 \%$ may be introduced by not considering cloud thickness.

Other cirrus retrieval approaches to obtain $\tau$ and $D_{e}$ use various combinations of visible (VIS) and near-infrared (NIR) reflectances (e.g., Dessler and Yang, 2003; Platnick et al., 2003; L'Ecuyer et al., 2006; Meyer et al., 2007; and references therein). The operational MODIS retrieval uses combinations of VIS/NIR window channels that are sensitive to clouds throughout the atmospheric column (Platnick et al., 2003). Although this approach excels at low cloud property retrievals over a large dynamic range of $\tau$ and $D_{e}$ unlike the thermal IR, the presence of underlying cloud layers under thin cirrus can introduce large biases in $\tau$ and $D_{e}$ (Davis, 2007). Biases caused by multi-layered cloud structures as viewed by the IR are generally smaller since they depend on relatively small thermal contrasts between the surface and low cloud. The MODIS $1.38 \mu \mathrm{m}$ band constrains cirrus $\tau$ more accurately than the operational approach because the underlying water vapor absorption either reduces or eliminates the reflectance contributed by low cloud layers (Meyer et al., 2007). However, this channel alone cannot constrain $D_{e}$ nor observe cirrus at nighttime. The lower limit of sensitivity to cirrus using the operational MODIS cloud mask is near $\tau \sim 0.3$, whereas the $1.38 \mu \mathrm{m}$ channel is much more sensitive to thin cirrus (Dessler and Yang, 2003) and more closely resembles the sensitivity of AIRS. Although any IR retrieval approach has its own set of limitations, it provides a global and diurnal view of cirrus $\tau$ and $D_{e}$ not available from the VIS/NIR methods.

\subsection{Validation of RTM inputs}

Several validation studies of AIRS Version 4 (V4) and Version 5 (V5) $T(z)$ and $q(z)$ profiles in the presence of varying amounts of clouds and clear sky have quantified their accuracy and precision throughout a significant variety of geophysical conditions (Divakarla et al., 2006; Tobin et al., 2006, 2007). Comparisons of AIRS $T(z)$ and $q(z)$ using Vaisala RS-90 radiosondes, determined to be of sufficient precision in and near UT ice clouds by Miloshevich et al. (2006), were launched at the ARM program sites and are discussed in Tobin et al. (2006). For the tropical Western Pacific site of Nauru Island, the mean bias of AIRS V4-ARM $T(z)$ from $100-400 \mathrm{hPa}$ is approximately $0.0 \mathrm{~K}$, although at a particular level the bias can be as large as $\pm 0.5 \mathrm{~K}$. The root mean square (RMS) is $0.5-1.0 \mathrm{~K}$ from the surface to $200 \mathrm{hPa}$ and increases to $1.0-2.0 \mathrm{~K}$ from $200 \mathrm{hPa}$ to the tropical tropopause in V4, but V5 is improved with reductions of $0.1-0.2 \mathrm{~K}$. Mean biases in $q(z)$ from the surface to $400 \mathrm{hPa}$ are near $0 \%$, although below $400 \mathrm{hPa}$, a dry bias of approximately $10 \%$ is shown for AIRS V4; in V5 this bias is near $0 \%$. RMS values for $q(z)$ are near $10 \%$ in the lower and 

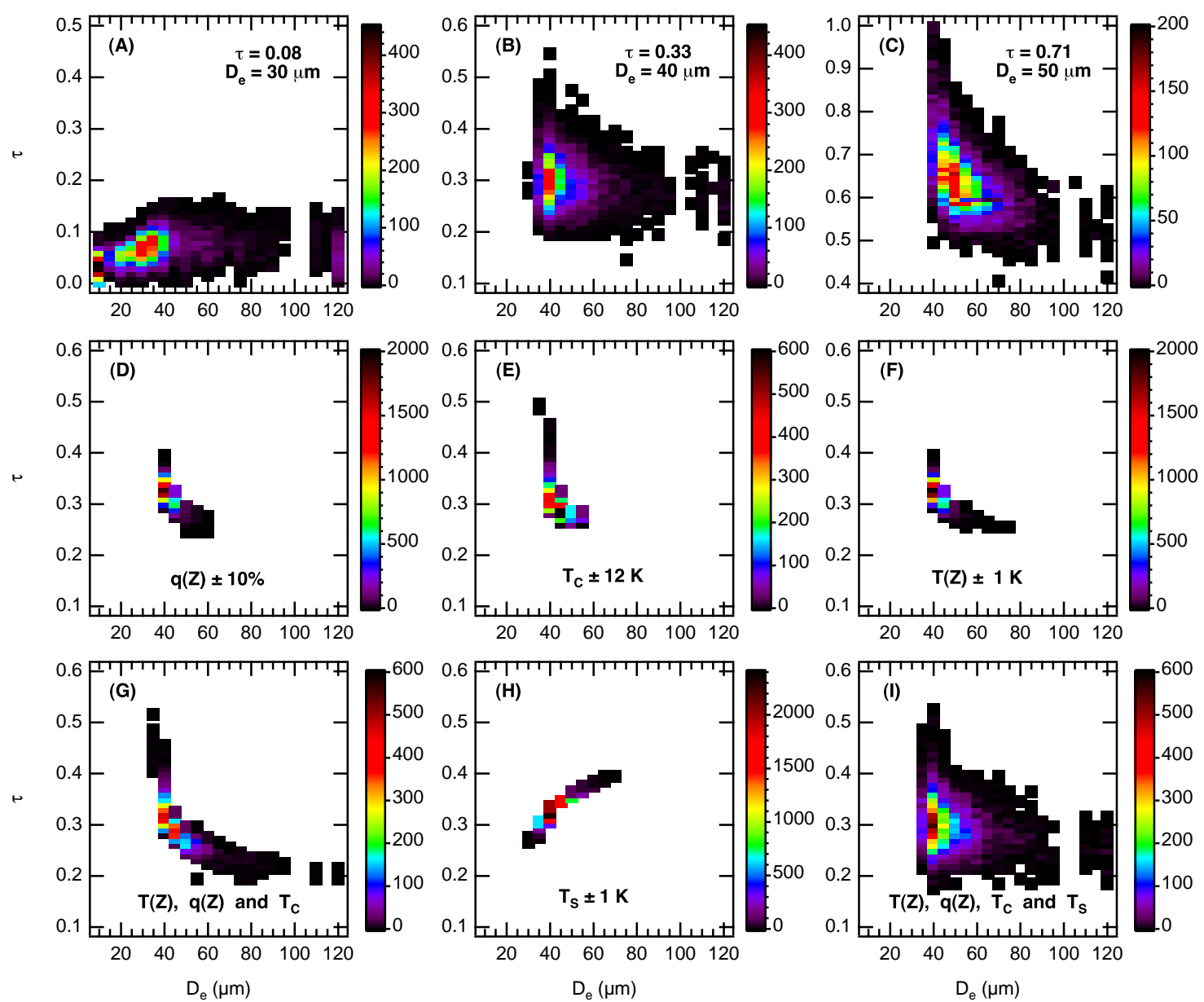

Fig. 4. Sensitivity of $\tau$ and $D_{e}$ to uncertainties in forward model inputs $T(z), q(z), T_{C}, T_{S}, \varepsilon$ and $\rho$ using normally-distributed $1 \sigma$ errors of $\pm 1 \mathrm{~K}, 10 \%, 12 \mathrm{~K}, 1 \mathrm{~K}, 0.01$, and 0.01 , respectively. Furthermore, $T_{C}$ is adjusted by a bias of $-12 \mathrm{~K}$ to be consistent with Fig. 3 . Both $T(z)$ and $q(z)$ errors are uniformly applied to all levels in the vertical profile. (A) Probability density function of $\tau$ and $D_{e}$ retrievals after addition of normally-distributed errors in all forward model inputs for $\tau=0.08$ and $D_{e}=30 \mu \mathrm{m}$, for granule 134, footprint (scan line) number 40 (97), on 9 April 2003. (B) same as (A) except for $\tau=0.33$ and $D_{e}=40 \mu \mathrm{m}$, footprint (scan line) number 41 (84). (C) Same as (A) except for $\tau=0.71$ and $D_{e}=50 \mu \mathrm{m}$, footprint (scan line) number 73 (110). (D-I) Errors for single and multiple quantities for retrieval described in (B); see Figs. for quantities used in calculation.

middle troposphere and increase to $20-30 \%$ between $300 \mathrm{hPa}$ and the tropopause in both V4 and V5. In summary, ARM comparisons with V5 show slight improvements over V4 for $T(z)$ and $q(z)$ in the tropical UT (Tobin et al., 2006, 2007).

The precision of cloud top height derived from AIRS was quantified with coincident cloud observations from the Cloud-Aerosol Lidar and Infrared Pathfinder Satellite Observation (CALIPSO) platform in Kahn et al. (2008) and comparisons for $f_{A} \leq 0.4$ are shown in Fig. 3. The bias is mostly invariant for clouds $\geq 7 \mathrm{~km}$ (determined by CALIPSO) for all $f_{A}$. During daytime (nighttime) the differences are 1.5$2.5 \pm 2-3 \mathrm{~km}(2.5-3.5 \pm 2.5-3.5 \mathrm{~km})$ with slightly higher variability for smaller $f_{A}$. The slightly higher differences found at nighttime are consistent with the increased sensitivity of the lidar in the absence of scattering from solar radiation. For clouds $<7 \mathrm{~km}$ (determined by CALIPSO), both the bias and variability are a strong function of $f_{A}$ with height differences between -6 to $-1 \pm 1.5-2.5 \mathrm{~km}$ for daytime and nighttime. The low height bias of $\sim 2 \mathrm{~km}$ in AIRS high clouds and the high height bias of $\sim 1-2 \mathrm{~km}$ in AIRS low and middle level clouds suggests some limitations in both the AIRS cloud retrieval algorithm and the sensitivity of near-nadir viewing infrared radiances. Furthermore, the large negative bias for $f_{A}<0.02$ demonstrates the presence of a significant number of spurious cloud retrievals near the tropopause (Kahn et al. 2008).

\subsection{Potential biases in thin cirrus retrievals}

Figure 4 shows the sensitivity of inferred $\tau$ and $D_{e}$ using validated uncertainties in the RTM inputs for three typical 
thin cirrus cases. Each probability density function (PDF) is calculated from 10000 randomly perturbed RTM inputs that are then propagated into the retrieval of $\tau$ and $D_{e}$ as outlined in Sect. 2.1 and Yue et al. (2007). The perturbed inputs include $T(z), q(z), T_{C}, T_{S}, \varepsilon$ and $\rho$, and are consistent with AIRS validation results with normally distributed $1 \sigma$ errors of $\pm 1 \mathrm{~K}, 10 \%, 12 \mathrm{~K}, 1 \mathrm{~K}, 0.01$, and 0.01 , respectively ( $\varepsilon$ and $\rho$ are mutually exclusive). The bias of $2.0-2.5 \mathrm{~km}$ in cloud top height is corrected by subtracting a constant $-12 \mathrm{~K}$ from $T_{C}$. Although $T(z)$ and $q(z)$ are uniformly scaled by $1 \mathrm{~K}$ and $10 \%$ errors, respectively, they are in practice a function of height, but more realistic error perturbations (e.g. Kahn et al., 2005) are not investigated here. Furthermore, the error perturbations assumed in Fig. 4 are not correlated between the different physical quantities, although non-zero co-variances may exist in the observed atmosphere. Thus, the calculated errors in $D_{e}$ and $\tau$ shown in Fig. 4 may be an overestimate since correlated errors will effectively reduce the width of the PDFs. However, the spatial and temporal dependences of cloud, atmospheric and surface uncertainties must be considered when quantifying the statistical significance of spatial and temporal differences in cirrus $\tau$ and $D_{e}$, including those that may arise from anthropogenic climate change and aerosol indirect effects (e.g. Chylek et al., 2006). This point is further highlighted in Sect. 3. Three typical thin cirrus cases are shown in Fig. $4 \mathrm{a}-\mathrm{c}$ with corresponding values of $\tau=0.08,0.33$, and 0.71, and $D_{e}=30,40$, and $50 \mu \mathrm{m}$. Figure $4 \mathrm{a}-\mathrm{c}$ demonstrate that the Gaussian retrieval "noise" of the RTM inputs leads to non-Gaussian variability in $\tau$ and $D_{e}$.

A case with multiple retrieval clusters (or modes) is illustrated in Fig. 4a ( $\tau=0.08$ and $\left.D_{e}=30 \mu \mathrm{m}\right)$ with the three modes centered at $D_{e}=10,30$, and $120 \mu \mathrm{m}$. Although the $30 \mu \mathrm{m}$ mode is expected because it is essentially the "noiseless" retrieval, the "spurious" modes at 10 and $120 \mu \mathrm{m}$ arise from a combination of imposing bounds on the range of simulated $D_{e}$ and RTM input noise. The PDF reveals that more scatter is observed in $D_{e}$ compared to $\tau$, although most values associated with the $30 \mu \mathrm{m}$ mode are within $\pm 5-10 \mu \mathrm{m}$, in approximate agreement with Yue et al. (2007). In Fig. 4b ( $\tau=0.33$ and $D_{e}=40 \mu \mathrm{m}$ ), more scatter is observed in $\tau$ compared to $D_{e}$, but most $\tau$ are within $\pm 0.07-0.08$. Nearly all $D_{e}$ are located within $\pm 5 \mu \mathrm{m}$, with a modicum of scatter extending to $100 \mu \mathrm{m}$ and a fairly sharp cut-off near $30 \mu \mathrm{m}$. In Fig. $4 \mathrm{c}\left(\tau=0.71\right.$ and $\left.D_{e}=50 \mu \mathrm{m}\right)$, the scatter is observed to be more extensive in both $\tau$ and $D_{e}$ when compared to Fig. $4 \mathrm{~b}$.

The characteristics of the thin cirrus retrieval noise may be dominated by particular atmospheric and surface quantities. To investigate this possibility, various combinations of $T(z)$, $q(z), T_{C}$, and $T_{S}$ are shown in Fig. $4 \mathrm{~d}-\mathrm{i}$ for the case detailed in Fig. 4b. Biases of $q(z), T(z)$ and $T_{C}$ have similar impacts, namely, that positive biases in $D_{e}$ are associated with compensating negative biases in $\tau$ and vice-versa (Fig. 4d-f; Huang et al., 2004). The physical cause is the spectral dependence of water vapor absorption in the atmospheric win- dows. For any increase (decrease) in the total column water vapor, the spectrum in Fig. 1 has a stronger (weaker) brightness temperature $\left(T_{b}\right)$ slope and lower (higher) overall $T_{b}$ from $800-1200 \mathrm{~cm}^{-1}$ (e.g. Kahn et al., 2004, 2005). Thus, an increase in $q(z)$ results in a smaller perceived $D_{e}$ (larger $T_{b}$ slope) and larger perceived $\tau$ (overall colder $T_{b}$ ) and viceversa; similar effects arise from noise in $T(z)$ and $T_{C}$. For $T_{S}$, the impact is the opposite of $q(z), T(z)$ and $T_{C}$ (Fig. $4 \mathrm{~h}$; Huang et al., 2004). When $T(z), q(z), T_{C}$, and $T_{S}$ are combined (Fig. 4i), the scatter becomes much broader than each quantity alone and takes on an increasingly non-Gaussian shape, but a large majority of $D_{e}$ and $\tau$ are found within $\pm 5 \mu \mathrm{m}$ and \pm 0.08 , respectively. This suggests the importance of constraining $T_{S}$ to minimize retrieval noise, perhaps with more precise microwave-derived SSTs over the ocean (Wentz et al., 2000), because it plays a key role in broadening the PDFs shown in Fig. 4. In summary, assumed Gaussian errors associated with RTM inputs that are propagated into a cirrus retrieval algorithm lead to (1) non-Gaussian retrieval noise in $D_{e}$ and $\tau,(2)$ unphysical modes that have changing characteristics as a function of the magnitude of $D_{e}$ and $\tau$, and (3) possible limitations in the interpretation of large sets of cirrus retrievals like those shown in Sect. 3.

\section{Results}

AIRS retrievals are presented for $\sim 2.5$ million optically thin, single-layered cirrus clouds over the tropical oceans $\pm 20^{\circ}$ latitude. A total of 29 days are used and are uniformly distributed over the four seasons (separated 48 days apart), starting 6 September 2002 and ending 4 June 2006. These days were selected to sample the entire seasonal cycle, to reduce computational limitations of a larger data set, and because of the constraints on the availability of AIRS V5 retrievals before public release. In Sect. 3.1, histograms of $D_{e}$ and $\tau$ are discussed and compared to retrievals from other surfaceand satellite-based platforms. Section 3.2 presents joint histograms of $D_{e}, \tau$, and $\mathrm{RH}_{\mathrm{i}}$, and spatial and seasonal variations of $\mathrm{RH}_{\mathrm{ic}}$ and cloud-clear sky $\mathrm{RH}_{\mathrm{i}}$ anomalies. Lastly, Sect. 3.3 illustrates the dependence of $\mathrm{RH}_{\mathrm{ic}}$ on cloud geometrical thickness using coincident CALIPSO data, and the interpretation of the relationship of $\mathrm{RH}_{\mathrm{ic}}$ to cloud-clear sky $\mathrm{RH}_{\mathrm{i}}$ anomalies.

\subsection{Thin cirrus properties}

Several important physical properties of thin cirrus are illuminated in Fig. 5. A peak frequency of occurrence is observed near $215-220 \mathrm{~K}$ for all values of $\tau$, and a much smaller peak near 190-195 K for $\tau<0.25$ (Fig. 5a). Although the vertical structure of thin cirrus resembles some activebased observations (e.g. Comstock et al., 2002), Fig. 5a shows that AIRS is limited in retrieving very thin cirrus within the TTL, consistent with the small lapse rates of $T(z)$ 

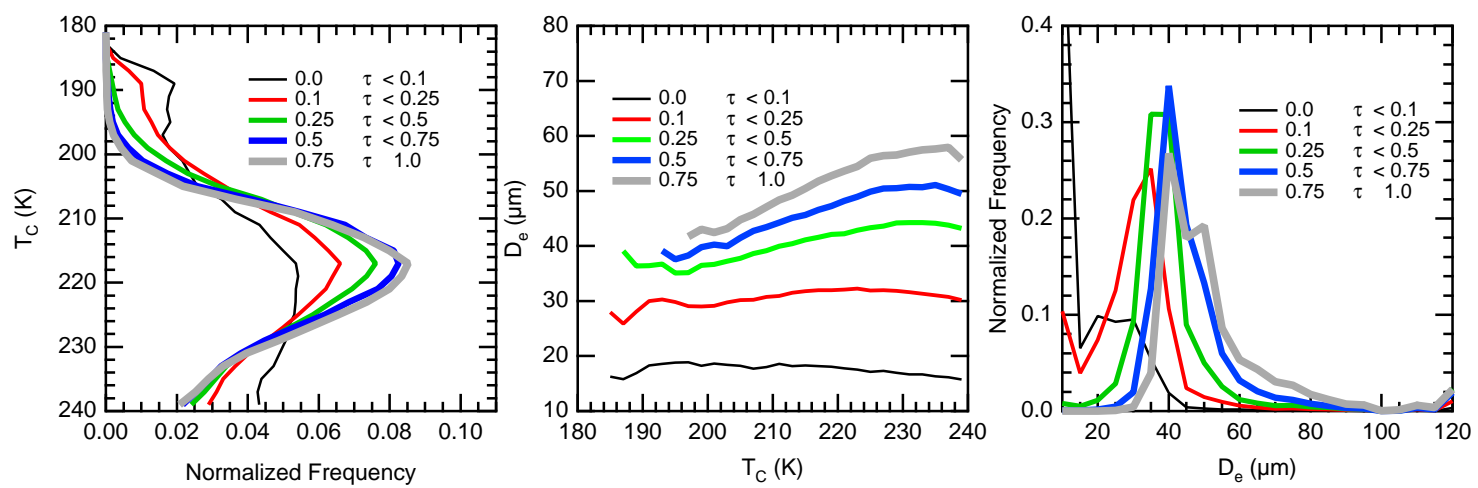

Fig. 5. (A) Normalized probability distribution of $T_{C}$ for all 29 focus days and $0.0<\tau \leq 1.0$. Potentially spurious cloud retrievals with $f_{A}<0.02$ are not included (see Fig. 3 and Kahn et al. 2008). Histograms are partitioned into 5 bins of $\tau(0.0-0.1,0.1-0.25,0.25-0.5$, 0.5-0.75, and 0.75-1.0). (B) Joint probability distributions of $T_{C}$ and $D_{e}$ for the same time period and $\tau$ intervals as (A). (C) Normalized histograms of $D_{e}$ for the same bins listed in (B). Bin width for (A-C) is $5 \mathrm{~K}$ and $5 \mu \mathrm{m}$ for $T_{C}$ and $D_{e}$, respectively.

typical of this region of the atmosphere. The small peak near $190-195 \mathrm{~K}$ is dominated by $\tau \leq 0.1$ and is largely within the range of the retrieval "noise" (Fig. 4). Furthermore, substantial uncertainties in $T_{C}$ for tenuous cirrus $(\tau \leq 0.1)$ are implied by a dispersed vertical profile relative to $\tau>0.1$ (Fig. 5a). Kahn et al. (2007a) show that clouds with $f_{A}<0.05$ (hence, small $\tau$ ) may have uncertainties of $50-100 \mathrm{hPa}$ or more that translate to $T_{C}$ uncertainties of $10 \mathrm{~s}$ of Kelvins, and a more dispersed profile.

Higher values of $\tau$ show a stronger correlation of $D_{e}$ and $T_{C}$ and vice-versa (Fig. 5b). Studies of surface (van Zadelhoff et al., 2004), aircraft (e.g. Garrett et al., 2003; Heymsfield et al., 2006; and references therein), and satellite-based (e.g. Stubenrauch et al., 2004; Mote and Frey, 2006) cirrus retrievals reveal similar relationships. In particular, Fig. 5b shows a striking similarity to TOVS-derived cirrus presented in Stubenrauch et al. (2004, their Fig. 5). In this study, the smallest bin of tropical ice water path (IWP) (analogous to small $\tau$ ) shows a maximum of $D_{e}$ near $220-225 \mathrm{~K}$ with slight reductions in $D_{e}$ for both warmer and colder $T_{C}$. For larger bins of IWP, $D_{e}$ increases gradually but consistently with increasing $T_{C}$. With regard to AIRS, a positive correlation of $D_{e}$ and $T_{C}$ is observed for $\tau>0.25$ and a broad maximum in $D_{e}$ is found for $\tau \leq 0.25$ (Fig. 5b). However, the magnitude of $D_{e}$ is greater in Stubenrauch et al. (2004) than shown in Fig. $5 \mathrm{~b}$ by $10-15 \mu \mathrm{m}$. This is unsurprising given that the retrievals presented herein are limited to thin cirrus. Also, the differences in AIRS and TOVS derived $D_{e}$ likely arise in some part to differences in instrument and algorithm characteristics. In van Zadelhoff et al. (2004) larger values of $D_{e}$ are derived from surface-based lidar-radar measurements compared to AIRS, although much thicker cirrus clouds are included $(\tau<4)$ that may preferentially contain larger $D_{e}$.

In Fig. 5c, histograms of $D_{e}$ are shown in order to quantify the scatter within each $\tau$ bin in Fig. 5b. Although significant overlap occurs between bins, the individual distributions are distinct and demonstrate a clear increase of $D_{e}$ with increasing $\tau$, consistent with the cited studies above. Large frequencies of $10 \mu \mathrm{m}$ retrievals for $\tau<0.1$ and a significant reduction for the next highest $\tau$ bin are consistent with the retrieval noise discussed in Sect. 2.3 but a fraction of these may be valid. Filtering "spurious" from "valid" cirrus retrievals requires at a minimum validated FOV-dependent error estimates, but they are not sufficiently precise at present in operational AIRS products. Additionally, the small frequency peak near $120 \mu \mathrm{m}$ is consistent with retrieval noise (Sect. 2.3). However, after screening AIRS cloud layers for the likeliest candidates of single-layer thin cirrus, the operational retrieval may not detect all overlapping water and ice cloud FOVs. The "missed" lower layer of water cloud may correspond to a reduction in the magnitude (or reversal of sign) of the spectral radiance slope (Yang et al., 2003), forcing a solution of $D_{e}$ near the upper size bound of $120 \mu \mathrm{m}$.

Figure 6 summarizes the annual mean spatial distributions of thin cirrus properties. Thin cirrus frequency resembles aspects of the distributions and magnitudes derived from other passive near nadir-viewing instruments (Fig. 6a) including the High-Resolution Infrared Radiation Sounder (HIRS) (Wylie et al., 1999), the Infrared Interferometer Spectrometer (IRIS) (Prabhakara et al., 1988), and MODIS (Dessler and Yang, 2003). Areas with lower frequencies of thin cirrus, in particular those within the Inter-Tropical Convergence Zone (ITCZ) and western Pacific warm pool are dominated by thicker clouds (Fig. 6b). Mean fields of $Z_{C}$ reveal a tendency for somewhat higher cloud tops along the ITCZ and within the western Pacific Ocean (Fig. 6c). A small scan-angle dependence in $Z_{C}$ is revealed, an average of about $0.5-1 \mathrm{~km}$ higher at $\pm 49^{\circ}$ compared to nadir view. The dependence is negligible with regard to the impact on the interpretation of the joint distributions of $T_{C}$ with other quantities. Annual mean $\mathrm{RH}_{\mathrm{ic}}$ is several percent higher in the tropical Northern Hemisphere (NH) with significant longitudinal 

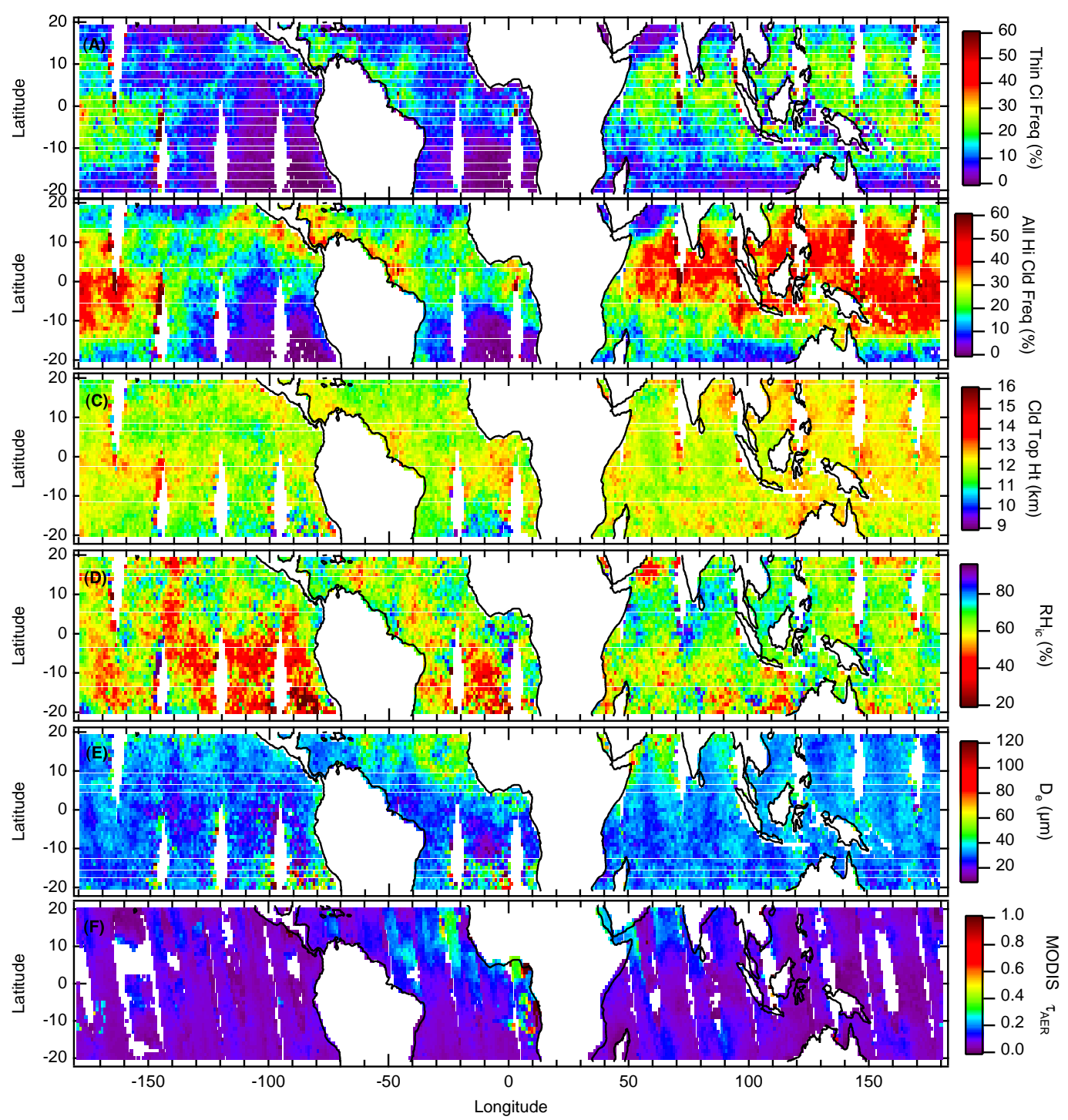

Fig. 6. Annual mean global oceanic values of (A) thin cirrus frequency $\left(0.02 \leq f_{A} \leq 0.4\right.$ and $\left.T_{C} \leq 240 \mathrm{~K}\right)$, (B) all cirrus cloud frequency $\left(0.02 \leq f_{A} \leq 1.0\right.$ and $\left.T_{C} \leq 240 \mathrm{~K}\right)$, (C) cloud top height $(\mathrm{km})$, (D) $\mathrm{RH}_{\mathrm{ic}}$ within thin cirrus shown in (A), (E) $D_{e}(\mu \mathrm{m})$, and $(\mathbf{F}) \mathrm{Moderate}$ Resolution Imaging Spectroradiometer (MODIS) total aerosol optical depth (Remer et al., 2005). All quantities are averaged to $1^{\circ} \times 1^{\circ}$ spatial resolution. The annual mean is formed from the set of 29 focus days.

variation and a distinct maximum in the $\mathrm{N}$. Indian Ocean basin (Fig. 6d). The calculation and interpretation of $\mathrm{RH}_{\mathrm{ic}}$ will be discussed in Sects. 3.2 and 3.3.

Corresponding patterns of $D_{e}$ (Fig. 6e) show that low spatial variability is observed except for higher values and variability found in (1) regions corresponding to low cirrus frequency in the southeastern Pacific and south Atlantic Oceans that also contain significant frequencies of overlapping cirrus and stratocumulus, and (2) the central Atlantic and northwestern Indian Ocean basins that contain high loadings of aerosol $\tau$ (Fig. 6f). As discussed earlier overlapping clouds may cause high biases in $D_{e}$; similarly, thin cirrus overlying a lower layer of dust may cause high biases from changes in the radiance spectrum (Hong et al., 2006). Table 1 shows the differences of averaged $D_{e}$ in the $\mathrm{NH}$ and $\mathrm{SH}$ with a second set of $D_{e}$ values reported for the NH that are screened for spatial regions with high averages of aerosol $\tau$. Interhemispheric differences in $D_{e}$ are shown to be smaller after screening for these regions, and they further illustrate that the thinnest cirrus is most sensitive to underlying aerosol contamination. However, a residual inter-hemispheric difference remains after aerosol screening and may suggest consistency with theories regarding impacts of heterogeneous ice nucleation on thin cirrus cloud frequency and $D_{e}$ (Kärcher, 2004). Before a robust conclusion can be drawn, cirrus retrievals must be extended both outside of the tropics and to optically 
Table 1. $D_{e}$ is shown as a function of hemisphere and $\tau$, but only for cirrus retrievals with $f_{A} \leq 0.02, q \geq 15$ ppmv, and AIRS quality flags $=0$ and 1. Values of $D_{e}$ are averaged over each hemisphere for all 29 focus days (unfiltered). The "filtered" version of $D_{e}$ in the NH screens out all observations bounded by $0-20^{\circ} \mathrm{N}$ and $45^{\circ} \mathrm{W}-0^{\circ} \mathrm{E}$ (near west coast of Africa), and $0-20^{\circ} \mathrm{N}$ and $45-105^{\circ} \mathrm{E}$ (N. Indian Ocean basin). By filtering these regions, a great majority of observations with MODIS $\tau_{\text {AER }}$ (at $2.13 \mu \mathrm{m}$ ) (Remer et al., 2005) between $0.1-0.5$ are removed.

\begin{tabular}{lccccc}
\hline & $\tau=0.0-0.1$ & $\tau=0.1-0.25$ & $\tau=0.25-0.5$ & $\tau=0.5-0.75$ & $\tau=0.75-1.0$ \\
\hline NH $D_{e}$ (unfiltered) & 18.64 & 33.10 & 42.53 & 47.72 & 53.02 \\
NH $D_{e}$ (filtered) & 17.62 & 31.99 & 41.95 & 47.41 & 52.89 \\
SH $D_{e}$ (unfiltered) & 17.48 & 31.44 & 41.63 & 46.73 & 51.92 \\
\hline
\end{tabular}
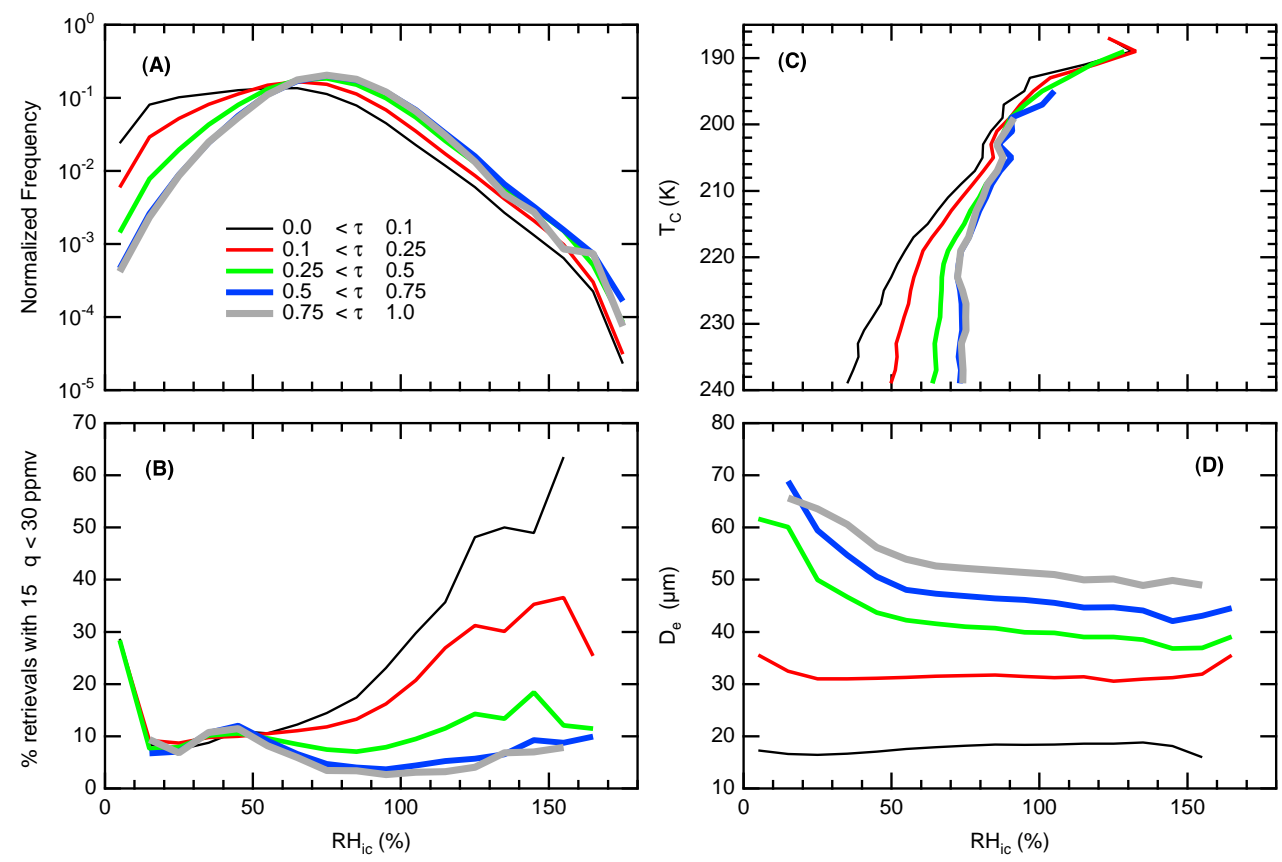

Fig. 7. (A) Normalized frequency distributions of $\mathrm{RH}_{\mathrm{ic}}$ binned into intervals of $0-10 \%, 10-20 \%, \ldots, 160-170 \%$. (B) Percentage of cases with $q$ (reported at level of $T_{C}$ ) between 15-30 ppmv; instances with $q<15$ ppmv not included because of the insensitivity and unreliability of q in dry conditions (Gettelman et al., 2004; Read et al., 2007). (C) $\mathrm{RH}_{\mathrm{ic}}$ vs. $T_{C}$ (K) for cases with $q \geq 15$ ppmv. (D) $\mathrm{RH}$ ic vs. $D_{e}$ ( $\mu \mathrm{m}$ ). All figures use the same $\tau$ bins introduced in Fig. 4. (B-D) show statistics for $\mathrm{RH}_{\mathrm{ic}}$ and $T_{C}$ bins that contain $\geq 100$ cirrus retrievals.

thicker clouds. Retrieval limitations with regard to overlapping dust and cirrus could be misinterpreted as an aerosol indirect effect on cirrus and stresses the importance of trustworthy error estimates and accounting for aerosol effects on cirrus retrievals.

\subsection{Joint distributions of thin cirrus and $\mathrm{RH}_{\mathrm{ic}}$}

Coincident $\mathrm{RH}_{\mathrm{ic}}$ within and near the thin cirrus described in Sect. 3.1 are derived from $T(z)$ and $q(z)$ following Gettelman et al. (2006). Profiles of $T(z)$ and $q(z)$ are generally reliable for $f_{A} \leq 0.7$ (Tobin et al. 2006). However, the highest meaningful altitude of $\mathrm{q}$ is closely tied to its magnitude since dry upper tropospheric regions induce radiances in corresponding water vapor sounding channels near radiance noise levels. Gettelman et al. (2004) showed with measure- ments from the Pre-AVE campaign that the sensitivity limit is around $q=10-20$ ppmv. In comparisons of spatially and temporally coincident $\mathrm{RH}_{\mathrm{i}}$ derived from AIRS and the Microwave Limb Sounder (MLS), values of $q<30$ ppmv may be of questionable quality (E. J. Fetzer, personal communication). A further analysis of $\mathrm{RH}_{\mathrm{i}}$ between AIRS and MLS by Read et al. (2007) suggests $q>20$ ppmv is reliable in the tropics.

Several important physical relationships between thin cirrus and $\mathrm{RH}_{\mathrm{ic}}$ are summarized in Fig. 7. Normalized frequency distributions of $\mathrm{RH}_{\mathrm{ic}}$ tend to be somewhat broader for smaller $\tau$, and peak frequencies are found between $\mathrm{RH}_{\mathrm{ic}}=60$ $80 \%$ with higher peak $\mathrm{RH}_{\mathrm{ic}}$ related to higher $\tau$ (Fig. 7a). The broad distributions of $\mathrm{RH}_{\mathrm{ic}}$ are suggestive that cirrus is geometrically thinner compared to the vertical resolution of $T(z)$ 

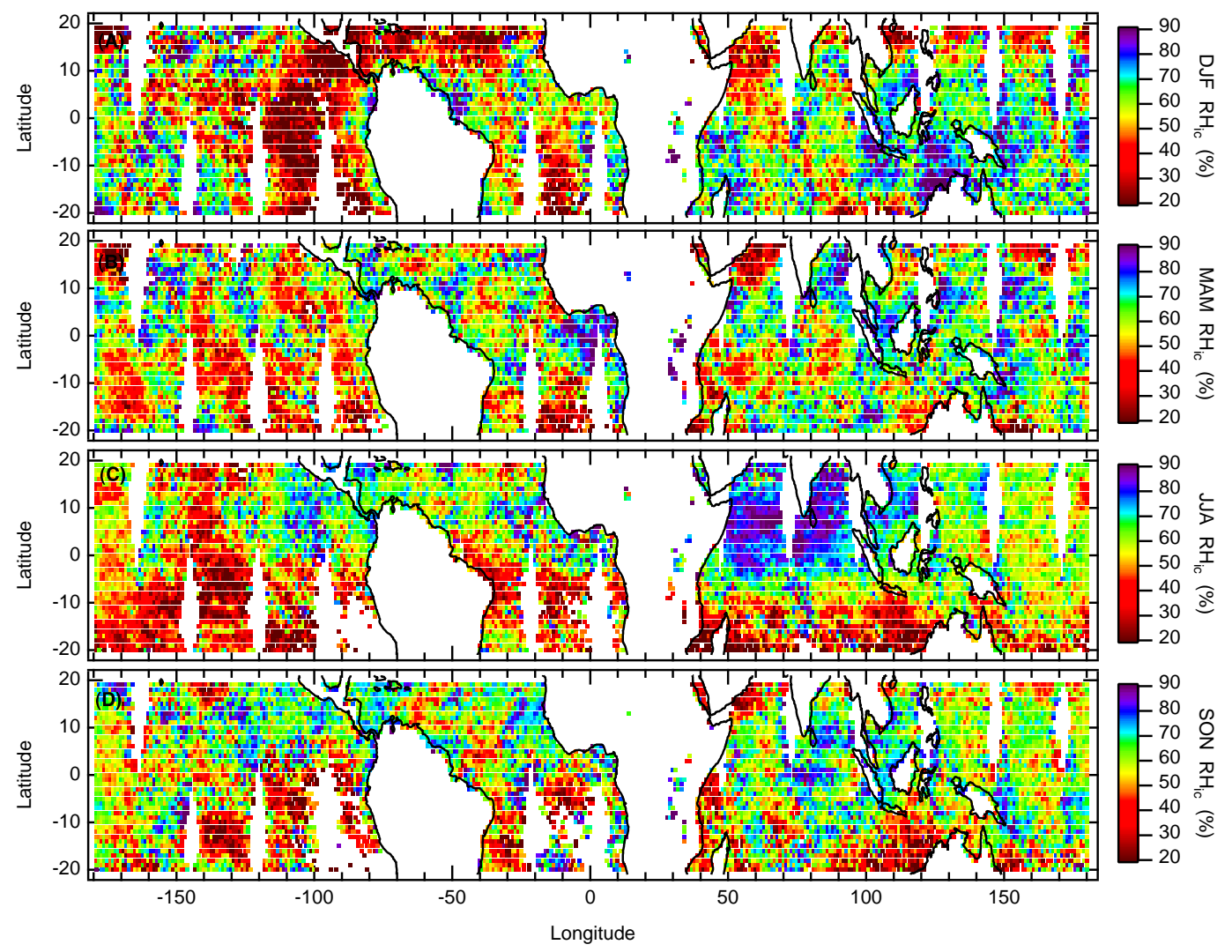

Fig. 8. Seasonal variability of $\mathrm{RH}_{\mathrm{ic}}$ over the global oceans ( 7 or 8 focus days for each season). From top to bottom: DJF, MAM, JJA, and $\mathrm{SON}$. All values of $\mathrm{RH}_{\mathrm{ic}}$ are averaged to $1^{\circ} \times 1^{\circ}$ spatial resolution.

and $q(z)$ (to be discussed in Sect. 3.3). The $\mathrm{RH}_{\mathrm{ic}}$ histogram with $\tau<0.1$ closely resembles all-sky distributions derived from TOVS (Gierens et al., 2004) and AIRS (Gettelman et al., 2006), and is consistent with the large percentage of spurious thin cirrus retrievals (Sect. 2.3). As $\tau$ increases, the frequency of very low $\mathrm{RH}_{\mathrm{ic}}$ reduces significantly. However, the distributions remain skewed towards $\mathrm{RH}_{\mathrm{ic}}<100 \%$ when compared to in situ measurements, including those from the Inter-hemispheric Differences in Cirrus Properties from Anthropogenic Emissions (INCA) campaign (Ovarlez et al., 2002; Ström et al., 2003; Gayet et al., 2004) that contain much fewer values of $\mathrm{RH}_{\mathrm{ic}}<80 \%$ than derived from AIRS.

The segment of the histogram with $\mathrm{RH}_{\mathrm{ic}} \geq 100 \%$ is generally invariant with $\tau$, but subtle differences in the shapes exist for $\mathrm{RH}_{\mathrm{ic}} \geq 120 \%$ (Fig. 7a). The observed distribution of supersaturation cannot be reproduced with validated biases and variability in AIRS $T(z)$ and $q(z)$ (Gierens and Spichtinger, 2004; Gettelman et al., 2006; Tobin et al., 2006). Inspection of Fig. 7a reveals that the frequency of $\mathrm{RH}_{\mathrm{ic}} \geq 120 \%$ is smaller relative to all-sky conditions (Gettelman et al., 2006). This is consistent with in situ observations (Ovarlez et al., 2002; Gayet et al., 2004) and modeling studies (e.g. Haag and Kärcher, 2003) that demonstrate the existence of upper bounds on $\mathrm{RH}_{\mathrm{ic}}$ consistent with heterogeneous or homogeneous nucleation or some mixture thereof. Although a well- defined "cut-off" is not observed in Fig. 7a like in Haag and Kärcher (2003), this is unsurprising given the global and tropical nature of the histograms, that the strongest anthropogenic "signal" is expected at higher latitudes (e.g. Ovarlez et al., 2002), and the inherent noise of $T(z)$ and $q(z)$ act to broaden the $\mathrm{RH}_{\mathrm{i}}$ distribution (Gettelman et al., 2006).

The sensitivity of the slope of the $\mathrm{RH}_{\mathrm{ic}}$ histograms to assumed thresholds of $q$ is quantified in Fig. 7b that shows the percentage of in-cloud $q$ between 15-30 ppmv. No values with $q<15$ ppmv are included for consistency with the sensitivity limitations suggested by Gettelman et al. (2004). For all values of $\tau$, about $5-15 \%$ of in-cloud observations are between 15-30 ppmv. The exception is for $\mathrm{RH}_{\mathrm{ic}}>80 \%$ and $\tau<0.25$, where $20-60 \%$ of observations are between $15-$ 30 ppmv, the precise value depending on the magnitude of $\mathrm{RH}_{\mathrm{i}}$ (Fig. 7b). Higher numbers of occurrences of q that approach the sensitivity limits of AIRS are observed for thin and cold cirrus near the base of the TTL. On one hand, this implies that the shape of the distribution of supersaturation within the optically thinnest clouds, hence the ability to discriminate between cirrus nucleation mechanisms, may be dependent on the estimate of AIRS water vapor sensitivity. On the other hand, this appears not to be important for cirrus with $\tau>0.25$. 

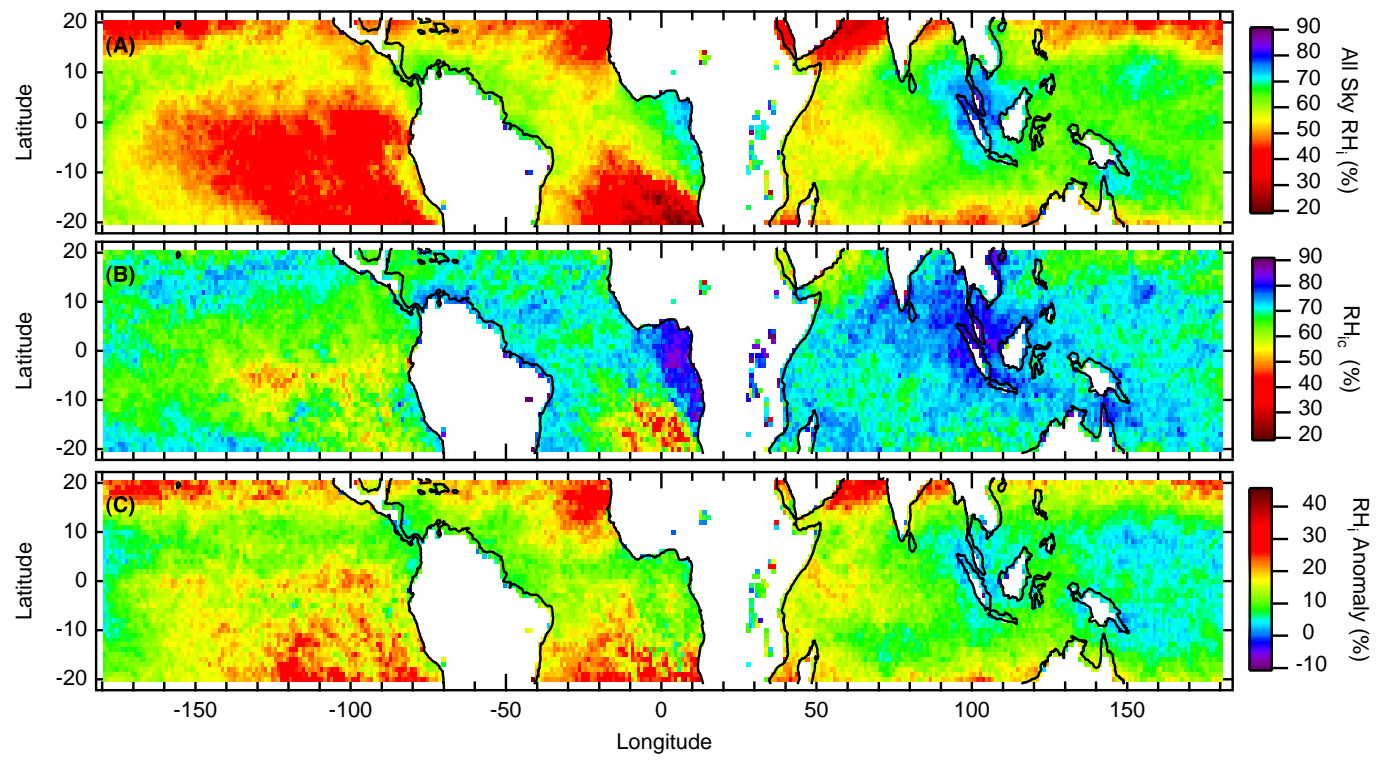

Fig. 9. (A) "All sky" $\mathrm{RH}_{\mathrm{i}}$ for the MAM period. "All sky" refers to thin cirrus and clear conditions (and not thicker clouds) defined at the cloud attitude that varies at the AIRS FOV-scale. The "all sky" $\mathrm{RH}_{\mathrm{i}}$ is calculated from mean $T(z)$ and $q(z)$ profiles in clear (defined by $f_{A}<0.02$ ) and thin cirrus skies for the MAM period in each $1 \times 1^{\circ}$ grid box. (B) $\mathrm{RH}_{\mathrm{ic}}$. (C) In-cloud - clear sky $\mathrm{RH}_{\mathrm{i}}$ anomaly. The anomaly is calculated by differencing (B) - (A) and is weighted by the relative frequency of clear sky occurrence within the grid box. The MAM climatology uses all days ( 270) in 2003-2005.

In Fig. 7c, $T_{C}$ decreases with increases in $\mathrm{RH}_{\mathrm{ic}}$, consistent with observations (Gettelman et al., 2006). The relationship of $D_{e}$ and $\mathrm{RH}_{\mathrm{ic}}$ is shown in Fig. 7d. While little dependence of $D_{e}$ on $\mathrm{RH}_{\mathrm{ic}}$ is observed for the smallest $\tau$ bins, it is observed for larger $\tau$, in particular the largest values of $D_{e}$ correspond to $\mathrm{RH}_{\mathrm{ic}}<50 \%$. These results are qualitatively consistent with the precipitation of large ice particles within sub-saturated air layers that have the potential to survive for several hours or more (Kay et al., 2006). In contrast, INCA observations show modest increases in $D_{e}$ that correspond to $\mathrm{RH}_{\mathrm{ic}}>100 \%$ (Gayet et al., 2004, their Fig. 6d). There is a very weak increase in $D_{e}$ with decreasing $\mathrm{RH}_{\mathrm{i}}$ near $\sim 80 \%$ in the INCA observations, qualitatively consistent with Fig. 7d, although this dependence may not be statistically significant. Despite the marginal significance according to the uncertainty estimates in Gayet et al. (2004), mutual increases in $D_{e}$ and $\mathrm{RH}_{\mathrm{ic}}$ are expected because of higher amounts of available water vapor for uptake to ice crystals. However, the INCA observations were sampled in SH and $\mathrm{NH}$ mid-latitudes over a more confined dynamic range of $T_{C}$ compared to this work. Furthermore, the observations of Gayet et al. (2004) are not necessarily samples of cirrus with low IWP or $\tau$ as viewed by a near nadir-viewing satellite. Given the aforementioned differences in the sampling and observing points of view, it is unsurprising that the characteristics of $D_{e}-\mathrm{RH}_{\mathrm{ic}}$ relationships differ between AIRS and those of Gayet et al. (2004). Understanding these discrepancies requires AIRS retrievals of thicker cirrus outside of the tropics, and is a topic of future research.
In summary, joint histograms of cirrus quantities and humidity obtained from a single sensor like AIRS allow for studies that are not constrained by temporal and spatial sampling differences inherent in aircraft in situ, surface, and multi-platform satellite analyses. This new capability facilitates a more robust investigation of the physical mechanisms that control the behavior of cloud and humidity distributions.

Global and seasonal distributions of $\mathrm{RH}_{\mathrm{ic}}$ are presented in Fig. 8. Although the limited number of days leads to some small-scale spatial variability, in general higher $\mathrm{RH}_{\text {ic }}$ corresponds to greater thin cirrus frequency (Fig. 6a) as in Sandor et al. (2000) and other studies. Furthermore, significant regional, hemispheric, and seasonal asymmetries are observed. The largest seasonal variations occur over the $\mathrm{N}$. Indian and N. E. Pacific Ocean basins, with the largest $\mathrm{RH}_{\mathrm{ic}}$ observed during JJA (Fig. 8c) over the N. Indian and DJF between Indonesia and Australia. Others such as the S. Indian and the central Pacific and Atlantic Oceans contain substantially less seasonal variability in $\mathrm{RH}_{\mathrm{ic}}$. A much larger set of in-cloud and clear sky $\mathrm{RH}_{\mathrm{i}}$ retrievals are shown for the MAM period from 2003-2005 in Fig. 9. The average $\mathrm{RH}_{\mathrm{ic}}$ is shown to be almost always greater than the all-sky (clear sky + thin cirrus) $\mathrm{RH}_{\mathrm{i}}$ average with the difference dependent on the location (Fig. 9a and b). In-cloud/clear sky $\mathrm{RH}_{\mathrm{i}}$ anomalies are largest in the fringes of the tropics transitioning to the subtropics, and near the coast of S. America, while the smallest values are observed near the ITCZ, the S. Pacific convergence zone, and throughout the tropical W. Pacific basin. The in-cloud/clear sky $\mathrm{RH}_{\mathrm{i}}$ differences tend to be largest in dry 


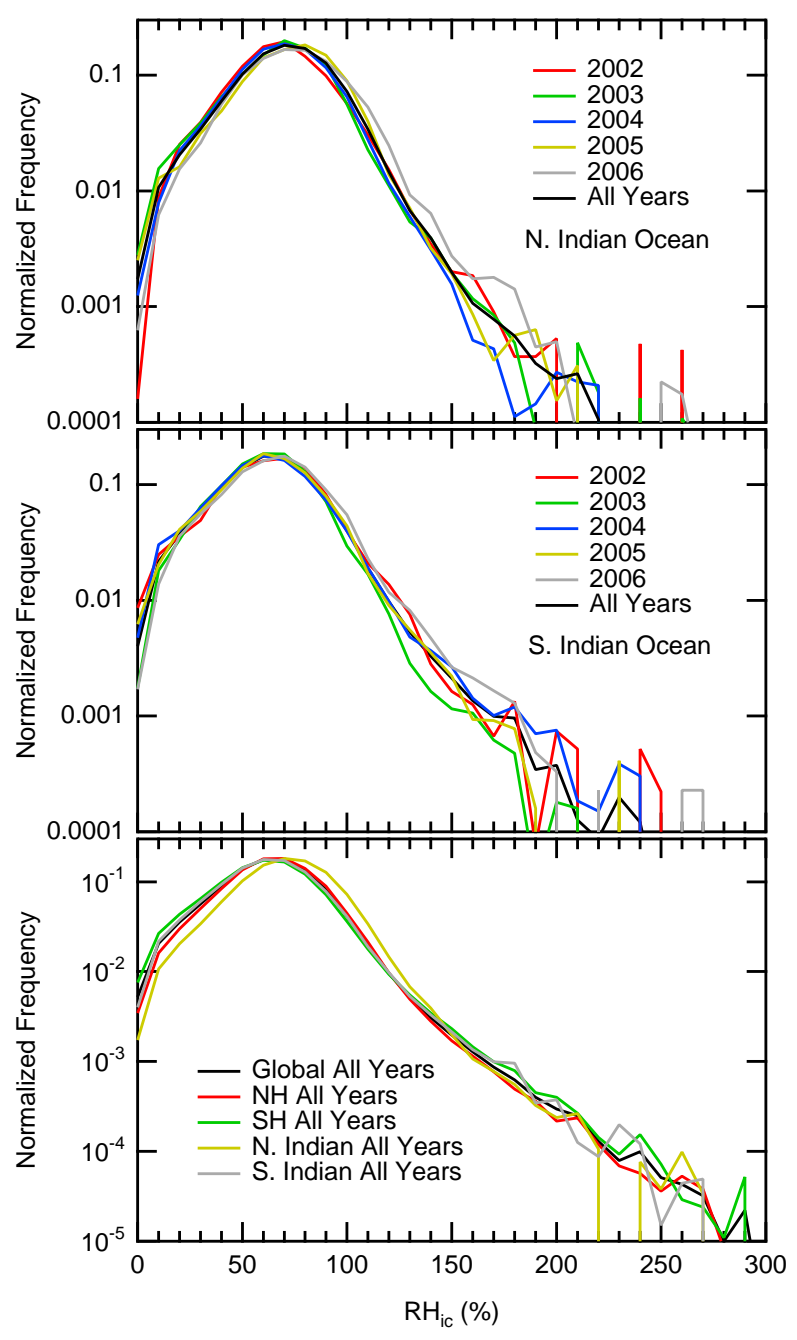

Fig. 10. (A) Normalized $\mathrm{RH}_{\mathrm{ic}}$ distributions over the N. Indian Ocean and partitioned by year (2002-2006). Results illustrated for all cirrus with $0.0 \leq \tau<1.0, q(z) \geq 15 \mathrm{ppmv}$, and $f_{A} \geq 0.02$. (B) same as (A) except for the $\mathrm{S}$. Indian Ocean. (C) Normalized $\mathrm{RH}_{\mathrm{ic}}$ distributions for the tropical ocean average $\left( \pm 20^{\circ}\right.$ latitude) (Fig. 7a) and for four sub-regions: the NH, SH, and N. and S. Indian Oceans. The total number of counts for the "All Years" histograms are $2.1 \times 10^{5}$, $2.4 \times 10^{5}$, and $1.44 \times 10^{6}$ for (A), (B), and (C), respectively.

regions dominated by subsidence in the fringes of the tropics and sub-tropics, but they are smallest in moist regions of frequent convection and upward motion in the deep tropics.

Some illustrations of observed regional and inter-annual variability in $\mathrm{RH}_{\mathrm{ic}}$ are shown in Fig. 10. In general, very small differences in the characteristics of $\mathrm{RH}_{\mathrm{ic}}$ distributions are observed between the $\mathrm{NH}, \mathrm{SH}$, and S. Indian Ocean basins compared to the global average. The exception is that $\mathrm{RH}_{\mathrm{ic}}$ is on average $\sim 10 \%$ greater over the $\mathrm{N}$. Indian Ocean (Fig. 10c). The inter-annual variations in $\mathrm{RH}_{\mathrm{ic}}$ for the same region are shown in Fig. 10a and they vary by $5-10 \%$ in the 2002-2006 period for $\mathrm{RH}_{\mathrm{ic}}<150 \%$. In contrast, the corre- sponding yearly variations in $\mathrm{RH}_{\mathrm{ic}}$ over the $\mathrm{S}$. Indian Ocean are shown to shift around $2-5 \%$ for $\mathrm{RH}_{\mathrm{ic}}<150 \%$ (Fig. 10b). Although the components contributing to the large variations of $\mathrm{RH}_{\mathrm{ic}}$ within the $\mathrm{N}$. Indian Ocean basin are uncertain, these regional variations can only be identified from the satellite point of view. Regional differences in cloud/clear sky $\mathrm{RH}_{\mathrm{i}}$ anomalies (Fig. 9c) are probably due in part to actual differences of $\mathrm{RH}_{\mathrm{ic}}$ and instrument and/or retrieval sensitivity as a function of geophysical scene type. To partly address this question, the relationship of geometrical cloud thickness $\left(\Delta Z_{c i}\right)$ to $\mathrm{RH}_{\mathrm{ic}}$ is addressed in Sect. 3.3.

\subsection{Vertical structure of thin cirrus and dry biases in $\mathrm{RH}_{\mathrm{ic}}$}

In situ observations of cirrus (e.g. Ovarlez et al., 2002; Ström et al., 2003; Gayet et al., 2004) consistently show that $\mathrm{RH}_{\mathrm{ic}}$ peaks in frequency around $100 \%$. In Sect. 3.2, AIRS retrievals were shown to vary between $60-80 \%$ with higher $\mathrm{RH}_{\mathrm{ic}}$ correlated to higher $\tau$ (Fig. 7a). However, some INCA observations indicate the existence of $\mathrm{RH}_{\mathrm{ic}}<70 \%$ within some very tenuous clouds (Spichtinger et al., 2004). In that study, the frequency of those observations is much less than comparable ones made with AIRS. Many of the clouds in sub-saturated conditions described in Spichtinger et al. (2004) are very tenuous and often occur at the edge of thicker clouds, and are probably below the AIRS sensitivity limits of detection and characterization. We investigate the hypothesis that $\Delta Z_{c i}$ can provide an explanation for the discrepancy in the frequency of low $\mathrm{RH}_{\mathrm{ic}}$. The nominal vertical resolution of AIRS-derived $\mathrm{RH}_{\mathrm{i}}$ is about $2-3 \mathrm{~km}$ but a majority of cirrus clouds have smaller values of $\Delta Z_{c i}$ (Comstock et al., 2002, their Fig. 8). Thus, for a typical and idealized single-layered cirrus cloud, any given observation of "incloud" $\mathrm{RH}_{\mathrm{i}}$ is some undetermined blend of clear air (likely to be dry) that is vertically adjacent to the cirrus layer (likely to be moist) resulting in a low bias of inferred $\mathrm{RH}_{\mathrm{ic}}$. However, more complicated vertical and horizontal humidity structures most certainly exist, for instance those in highly supersaturated clear sky adjacent to cirrus (Jensen et al., 2005). To quantify the relationship between $\Delta Z_{c i}$ and $\mathrm{RH}_{\mathrm{ic}}$, observations of cloud vertical structure from the Cloud-Aerosol LIdar with Orthogonal Polarization (CALIOP) (Winker et al., 2007), located on the CALIPSO platform, are collocated to AIRS FOVs to identify a set of single-layered cirrus that extend over the entire AIRS FOV.

Results are presented for both the global $\left( \pm 70^{\circ}\right)$ and tropical $\left( \pm 20^{\circ}\right)$ ocean basins (Fig. 11). Over the global oceans, the mean $\mathrm{RH}_{\mathrm{ic}}$ increases from $60 \%$ to $85 \%$ for $\Delta Z_{c i}$ increases of 0.2 to $3 \mathrm{~km}$ while at higher values $\mathrm{RH}_{\mathrm{ic}}$ slightly decreases. Over the tropical oceans, the mean $\mathrm{RH}_{\mathrm{ic}}$ increases from $60 \%$ to $90 \%$ for $\Delta Z_{c i}$ increases of 0.5 to $4 \mathrm{~km}$, a change of $30 \%$ over the range of $\Delta Z_{c i}$. The larger overall $\mathrm{RH}_{\mathrm{ic}}$ over the global oceans is consistent with a greater frequency of ice supersaturation in the mid-latitudes compared to the tropics as observed by nadir-viewing satellites (Gierens et al., 2004; 


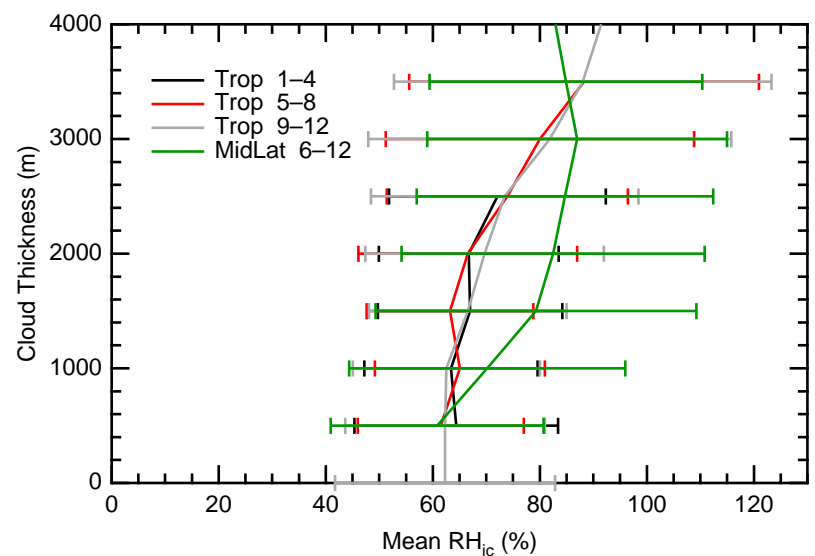

Fig. 11. Relationship of $\mathrm{RH}_{\mathrm{ic}}$ to geometrical cirrus cloud thickness derived from collocated AIRS-CALIPSO observations (Kahn et al., 2008). Only oceanic AIRS FOVs containing single-layered clouds with $0.02 \geq f_{A} \geq 0.4$ for $\pm 70^{\circ}$ lat (green) and $\pm 20^{\circ}$ lat (gray, red, and black) are used. For the tropics, three bins are defined that are based on the number of coincident $5 \mathrm{~km}$ CALIPSO lidar-detected cloud features $(1-4,5-8,9-12)$ within the AMSU FOV. For all latitudes, one bin with 6-12 coincident cloud features is shown. Horizontal bars indicate $1 \sigma$ variability for each $0.5 \mathrm{~km}$ cloud geometrical thickness bin. Cloud thickness bins containing less than 40 values not included.

Gettelman et al., 2006). Therefore, the mutual increases of $\mathrm{RH}_{\mathrm{ic}}$ and $\Delta Z_{c i}$ demonstrate that low biases of $\mathrm{RH}_{\mathrm{ic}}$ occur for a majority of thin cirrus. Furthermore, Fig. 11 demonstrates the negligible effects of horizontal cloud heterogeneity on the relationship between $\mathrm{RH}_{\mathrm{ic}}$ and $\Delta Z_{c i}$. For AMSU FOVs over the tropical oceans with varying degrees of horizontal cloud heterogeneity as defined by the $5 \mathrm{~km}$ CALIPSO cloud feature mask, the correspondence of $\mathrm{RH}_{\mathrm{ic}}$ and $\Delta Z_{c i}$ is virtually independent of horizontal cloud heterogeneity when $f_{A} \leq 0.4$. Values of $f_{A}>0.4$ suggest that there is some dependence of $\mathrm{RH}_{\mathrm{ic}}$ and $\Delta Z_{c i}$ on horizontal cloud heterogeneity (not shown), but it is not entirely clear if these are a result of biases in $\mathrm{RH}_{\mathrm{ic}}$ retrievals within thicker clouds; this remains the subject of future work. These results are consistent with biases introduced by the geometrical thinness of cirrus relative to the vertical resolution of $\mathrm{RH}_{\mathrm{ic}}$ that swamp any effects due to horizontal cloud heterogeneity. Upon first inspection of Fig. 11, the feasibility of a "correction factor" to simultaneous observations of $\mathrm{RH}_{\mathrm{ic}}$ and CALIOP-derived $\Delta Z_{c i}$ is suggested. Although this may be possible on the regional scale using large sets of observations, the large scatter in $\mathrm{RH}_{\mathrm{ic}}$ implies this is not the case for individual AIRS retrievals.

An additional candidate that may cause a dry bias in $\mathrm{RH}_{\mathrm{ic}}$ is the high bias in AIRS-derived $T_{C}$ (or low bias in cloud top height), illustrated in Fig. 3. Rather than applying an ad hoc correction to $T_{C}$ to compensate for the bias, we employ a more rigorous approach using the $\mathrm{L} 25 \mathrm{~km}$ CALIPSO

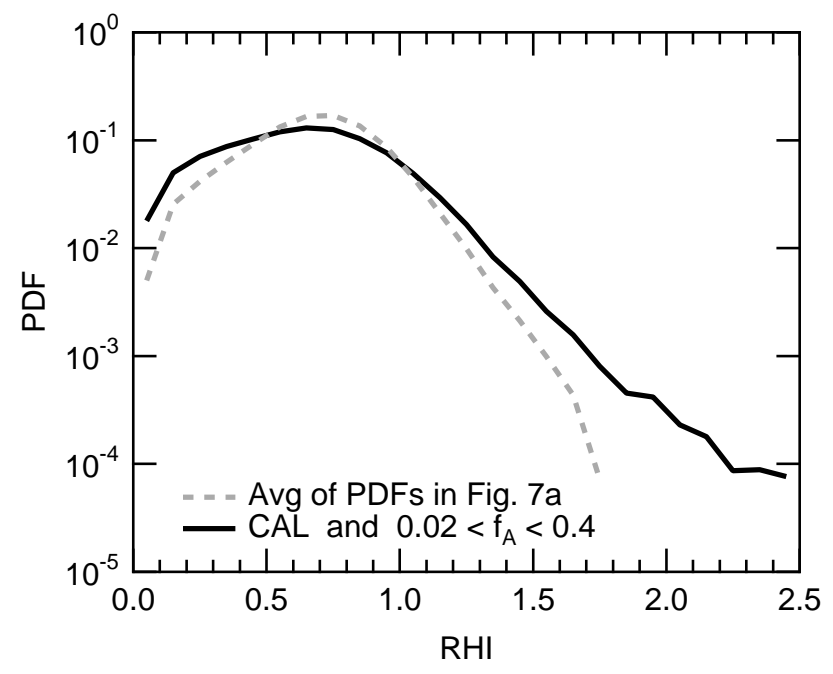

Fig. 12. Mean $\mathrm{RH}_{\mathrm{ic}}$ distribution from Fig. 7a averaged over all $\tau$ bins (dotted gray), and the $\mathrm{RH}_{\mathrm{ic}}$ distribution for clouds that are observed by CALIPSO, constrained to AIRS-observations with $0.02<f_{A}<0.4$, for July 2006 (solid black). $\mathrm{RH}_{\mathrm{ic}}$ is interpolated (log-linear) to all height bins located between cloud tops and bases identified in the CALIPSO L2 CLay $5 \mathrm{~km}$ product.

cloud feature mask to determine the altitudes at which $\mathrm{RH}_{\mathrm{ic}}$ is to be calculated throughout the depth of all cloud layers. In Fig. 12, results for July 2006 are shown and compared to the average $\mathrm{RH}_{\mathrm{ic}}$ distribution derived from Fig. 7a. The value of $\mathrm{RH}_{\mathrm{ic}}$ that contains the peak frequency is at most 5\% drier using the CALIPSO cloud profiles. Although the days used in Figs. 7 and 12 are not identical, the temporal sampling induces little sensitivity in $\mathrm{RH}_{\mathrm{ic}}$ (not shown). The $\mathrm{RH}_{\mathrm{ic}}$ distribution using AIRS $T_{C}$ contains fewer of the moist and dry observations compared to the CALIPSO-derived distribution. In summary, when using the entire cloud profile to calculate $\mathrm{RH}_{\mathrm{ic}}$ distributions, there is little to no change in the mean bias compared to the $T_{C}$-derived distributions. Rather, this approach demonstrates that a higher amount of dry and moist variability is captured, but only by sampling the entire cloud layer. Further reconciliation of cloud vertical structure with AIRS-derived humidity, for instance quantifying the spatial correlations of $\mathrm{RH}_{\text {ic }}$ and $\Delta Z_{c i}$ to help isolate the existence of other mechanisms that cause regional differences in Figs. 8-10, is a subject of ongoing research.

\section{Summary and discussion}

Observations of upper tropospheric microphysical, optical, and bulk cloud properties on the global scale, along with in-cloud and clear sky relative humidity are important for monitoring aspects of Earth's climate, and for evaluating and improving simulations of future climate change. In this work, distributions of thin cirrus optical depth $(\tau)$, effective 
diameter $\left(D_{e}\right)$, and relative humidity with respect to ice $\left(\mathrm{RH}_{\mathrm{i}}\right)$ within cirrus $\left(\mathrm{RH}_{\mathrm{ic}}\right)$ over the tropical oceans are simultaneously derived from the Atmospheric Infrared Sounder (AIRS). A rapid radiative transfer model (RTM) that is coupled to a thin cirrus parameterization is used to simultaneously retrieve thin cirrus $\tau$ and $D_{e}$ using a least-squares minimization method applied to simulated and observed AIRS spectral radiances between $8-12 \mu \mathrm{m}$ (Yue et al., 2007). The retrieval approach is applied to $\sim 2.5$ million observations of single-layer thin cirrus over the tropical oceans. The RTM uses available AIRS Version 5 L2 Standard and Support products to represent the atmospheric, surface, and cloudy states needed for the inference of $\tau$ and $D_{e}$. Results of recent AIRS Version 4 and 5 validation studies relevant to the RTM inputs and retrieval approach are summarized.

Cloud top temperature $\left(T_{C}\right)$ frequency statistics for thin cirrus reveal a dominant mode that peaks between 215$220 \mathrm{~K}$ and is associated with convective detrainment, while a much less dominant mode near $190-195 \mathrm{~K}$ is observed near the base of the tropical transition layer (TTL). The vertical cloud structure of thin cirrus derived from AIRS highlights strengths and limitations in using passive infrared radiances to infer thin cirrus quantities near to and within the TTL. Joint increases in $D_{e}$ and $T_{C}$ are shown for cirrus with $\tau>0.25$, consistent with other results based on surface, in situ and satellite retrievals. It is shown that numerous thin cirrus with $\tau<0.1-0.2$ are spurious because of limitations in the RTM inputs. This limitation is quantified by propagating the validated uncertainties in the atmospheric, surface, and cloudy inputs through the RTM and cirrus retrieval.

The methodology of Gettelman et al. (2006) is used to derive $\mathrm{RH}_{\mathrm{i}}$ within (and outside of) cirrus. In-cloud supersaturation is observed for $8-12 \%$ of thin cirrus in the tropics and is several factors greater than reported in all-sky conditions (Gettelman et al., 2006). Even higher frequencies of supersaturation occur for the coldest cirrus. The shape of $\mathrm{RH}_{\mathrm{ic}}$ frequency distributions is shown to depend on $\tau$ with a peak frequency located between $60-80 \%$, and higher values of $\mathrm{RH}_{\mathrm{ic}}$ are associated with larger $\tau$. Comparisons of in situ and AIRS-derived $\mathrm{RH}_{\mathrm{ic}}$ illustrate AIRS has a dry bias within cirrus, much more so for $\tau<0.25$. Although distributions of in situ and AIRS $\mathrm{RH}_{\mathrm{ic}}$ have similar characteristics, a consistently broader distribution is observed for AIRS.

We hypothesize that the dry bias is directly a consequence of the geometrical thickness $\left(\Delta Z_{c i}\right)$ for a majority of cirrus being less than the vertical resolution of AIRS temperature $T(z)$ and humidity $q(z)$ profiles $(\sim 2-3 \mathrm{~km})$. This is confirmed with coincident cloud vertical structure observed by the Cloud-Aerosol Lidar and Infrared Pathfinder Satellite Observation (CALIPSO). Both $\mathrm{RH}_{\mathrm{ic}}$ and $\Delta Z_{C}$ correspondingly increase until the nominal vertical resolution of AIRS is reached. Thus, the narrow extent of $\Delta Z_{c i}$ compared to the broad vertical resolution of $T(z)$ and $q(z)$ complicates the interpretation of $\mathrm{RH}_{\mathrm{ic}}$. $\mathrm{RH}_{\mathrm{ic}}$ is systematically biased low because of vertical smoothing over clear (likely dry) and cloudy (likely moist) layers, although real geophysical variability most certainly includes much more complicated vertical and horizontal humidity structures. Furthermore, the frequency of supersaturation in cirrus is mostly insensitive to assumptions about the minimum sensitivity of AIRS water vapor when $\tau>0.25$, thus the shape of $\mathrm{RH}_{\mathrm{ic}}$ generally appears to be robust.

Global distributions of $\mathrm{RH}_{\mathrm{ic}}$ have significant seasonal, latitudinal, and regional variations that correspond to large-scale dynamical variability, cirrus frequency, and clear sky/incloud $\mathrm{RH}_{\mathrm{i}}$ anomalies. The smallest (largest) anomalies tend to occur in moist (dry) regions associated with regions of vertical ascent (descent). The temporal and spatial differences in correlations between $\tau, D_{e}$, and $\mathrm{RH}_{\mathrm{ic}}$ may indicate fundamental differences in these joint relationships. In particular, slightly larger values of $D_{e}$ in the $\mathrm{NH}$ compared to the $\mathrm{SH}$ could suggest consistency with theories regarding impacts of heterogeneous ice nucleation on thin cirrus cloud frequency and $D_{e}$ (Kärcher, 2004). However, retrievals must be extended outside of the tropics and to thicker cirrus, and a thorough error analysis including aerosol effects must be calculated before a robust conclusion can be made. Furthermore, the $\mathrm{N}$. Indian Ocean basin has a $\sim 10 \%$ high bias in $\mathrm{RH}_{\mathrm{ic}}$ compared to the global average and substantial inter-annual variations of 5-10\% in average $\mathrm{RH}_{\mathrm{ic}}$ not seen elsewhere.

The cloud and humidity distributions presented herein demonstrate that AIRS provides a unique perspective on temporal and spatial variations of clouds and water vapor not available from any other aircraft in situ, surface, or contemporary satellite observing platform. Investigations of the physical mechanisms that control the behavior of joint cloud and humidity distributions using a single sensor are not constrained by temporal and spatial sampling differences inherent in multi-platform, surface-based, and in situ aircraft analyses. Although in situ measurements have established fundamental relationships of $D_{e}$ and $\mathrm{RH}_{\mathrm{ic}}$, AIRS now provides a global view within a vast variety of geophysical conditions. The joint distributions will be useful towards investigating mechanisms of cirrus formation and maintenance, evaluating and improving climate model parameterizations of ice cloud processes, and quantifying the radiative effects of thin cirrus largely composed of small ice crystals (e.g. McFarquhar et al., 2000; Garrett et al., 2003).

Future work must also take into account estimates of uncertainty of joint cirrus and humidity properties at the AIRS FOV-scale. A few general approaches are possible, including (1) the propagation of scene-dependent error estimates through single FOV retrievals, or (2) the replacement of atmospheric, surface, and cloud quantities with other sources of satellite observation. Method (1) will require further advances in AIRS error estimation for practical application. However, method (2) is feasible with the current A-train configuration and operational and research-mode generation of retrieval products. For instance, $\tau, D_{e}$, and $T_{C}$ derived from CALIPSO and MODIS can be used in synergy with 
AIRS to form a range of uncertainty in the joint distributions to investigate whether they are fundamentally similar or dissimilar regardless of the instrument used. For $T(z)$ and $q(z)$, global NWP models or instruments like MLS can be used with AIRS, although the vertical structure of $q(z)$ from model forecasts are problematic despite reasonable total column water vapor, and MLS only retrieves $T(z)$ and $q(z)$ in the upper troposphere and hiher in altitude. For $T_{S}$, microwave-derived SSTs may be useful over oceanic regions (e.g. Wentz et al., 2000). Other observing platforms may be used as well.

The estimates of uncertainty will provide more robust conclusions of inter-hemispheric, regional, and temporal variations in joint cirrus and humidity distributions, and a greater certainty of the physical mechanisms that control their structure. Future work includes extending this analysis to regions outside of the tropics, to thicker cirrus clouds using a radiative transfer model with multiple scattering, and to clouds with more complicated vertical configurations. Swath instruments like AIRS and MODIS provide the ability to use Lagrangian parcel trajectories to track cirrus cloud origin and evolution (e.g. Massie et al., 2002; Mace et al., 2006). The combination of AIRS-derived cloud and humidity distributions with other A-train observations is expected to yield many additional insights about the upper troposphere.

Acknowledgements. B. H. Kahn was supported by a NASA Postdoctoral Program fellowship during this study and acknowledges the NASA radiation sciences program directed by $\mathrm{H}$. Maring. C. K. Liang acknowledges the support of Northrup Grumman. A. Gettelman was supported by NASA grant EOS-03-0594-0572. The authors thank the AIRS and CALIPSO teams for technical assistance and public release of data products, T. Ackerman, E. Fetzer, A. Fridlind, J. Kay, A. Nenes, W. Read and R. Wood for helpful insights obtained through personal communication, A. Dessler for the suggestion of investigating cirrus geometrical thickness and humidity using coincident AIRS and CALIPSO observations, and two anonymous reviewers for helpful comments. AIRS data were obtained through the Goddard Earth Sciences Data and Information Services Center (http://daac.gsfc.nasa.gov/). CALIPSO data were obtained through the Atmospheric Sciences Data Center (ASDC) at NASA Langley Research Center (http://eosweb.larc.nasa.gov/). This work was performed at the Jet Propulsion Laboratory, California Institute of Technology, under contract with NASA.

Edited by: T. Garrett

\section{References}

Aumann, H. H., Chahine, M. T., Gautier, C., et al.: AIRS/AMSU/HSB on the Aqua mission: Design, science objectives, data products, and processing systems, IEEE Trans. Geosci. Remote Sensing, 41, 253-264, 2003.

Baker, M. B.: Cloud physics and climate, Science, 276, 1072-1078, 1997.

Baran, A. J. and Francis, P. N.: On the radiative properties of cirrus cloud at solar and thermal wavelengths: A test of model consistency using high-resolution airborne radiance measurements, Q. J. Roy. Meteor. Soc., 130, 763-778, 2004.

Baum, B. A., Yang, P., Nasiri, S., Heidinger, A. K., Heymsfield, A., and Li, J.: Bulk scattering properties for the remote sensing of ice clouds, Part III: High-resolution spectral models from 100 to $3250 \mathrm{~cm}^{-1}$, J. Appl. Meteor. Climatol., 46, 423-434, 2007.

Boehm, M. T. and Verlinde, J.: Stratospheric influence on upper tropospheric tropical cirrus, Geophys. Res. Lett., 27, 3209-3212, 2000.

Chylek, P., Dubey, M. K., Lohmann, U., Ramanathan, V., Kaufman, Y. J., Lesins, G., Hudson, J., Altmann, G., and Olsen, S. C.: Aerosol indirect effect over the Indian Ocean, Geophys. Res. Lett., 33, L06806, doi:10.1029/2005GL025397, 2006.

Clark, H. L.: Longitudinal variability of water vapor and cirrus in the tropical tropopause layer, J. Geophys. Res., 110, D07107, doi:10.1029/2004JD004943, 2005.

Comstock, J. M., Ackerman, T. P., and Mace, G. G.: Ground-based lidar and radar remote sensing of tropical cirrus clouds at Nauru Island: Cloud statistics and radiative impacts, J. Geophys. Res., 107, 4714, doi:10.1029/2002JD002203, 2002.

Comstock, J. M., Ackerman, T. P., and Turner, D. D.: Evidence of high ice supersaturation in cirrus clouds using ARM Raman lidar measurements, Geophys. Res. Lett., 31, L11106, doi:10.1029/2004GL019705, 2004.

Cooper, S. J., L'Ecuyer, T. S., Gabriel, P., Baran, A. J., and Stephens, G. L.: Objective assessment of the information content of visible and infrared radiance measurements for cloud microphysical property retrievals over the global oceans. Part II: Ice clouds, J. Appl. Meteor. Climatol., 45, 42-62, 2006.

Davis, S. M.: Airborne in situ measurements of cirrus cloud total water using a laser hygrometer and inter-comparisons with satellite observations, Ph.D thesis, University of Colorado - Boulder, 278 pp., 2007.

DeMott, P. J., Cziczo, D. J., Prenni, A. J., Murphy, D. M., Kreidenweis, S. M., Thomson, D. S., Borys, R., and Rogers, D. C.: Measurements of the concentration and composition of nuclei for cirrus formation, Proc. Natl. Acad. Sci. USA, 100, $14655-$ $14660,2003$.

Dessler, A. E. and Yang, P.: The distribution of tropical thin cirrus clouds inferred from Terra MODIS data, J. Climate, 16, 12411247, 2003.

Divakarla, M. G., Barnet, C. D., Goldberg, M. D., McMillin, L. M., Maddy, E., Wolf, W., Zhou, L., and Liu, X.: Validation of Atmospheric Infrared Sounder temperature and water vapor retrievals with matched radiosonde measurements and forecasts, J. Geophys. Res., 111, D09S15, doi:10.1029/2005JD006116, 2006.

Forster, P., Ramaswamy, V., Artaxo, P., et al.: Changes in atmospheric constituents and in radiative forcing, Climate Change 2007, in: The Physical Science Basis, Contribution of Working Group I to the Fourth Assessment Report of the IPCC, edited 
by: Solomon, S., Quin, D., Manning, M., et al., Cambridge University Press, Cambridge, United Kingdom and New York, NY, USA, 129-234, 2007.

Garrett, T. J., Gerber, H., Baumgardner, D. G., Twohy, C. H., and Weinstock, E. M.: Small, highly reflective ice crystals in low-latitude cirrus, Geophys. Res. Lett., 30(21), 2132, doi:10.1029/2003GL018153, 2003.

Gayet, J.-F., Ovarlez, J., Shcherbakov, V., et al.: Cirrus cloud microphysical and optical properties at southern and northern midlatitudes during the INCA experiment, J. Geophys. Res., 109, D20206, doi:10.1029/2004JD004803, 2004.

Gettelman, A., Weinstock, E. M., Fetzer, E. J., et al.: Validation of Aqua satellite data in the upper troposphere and lower stratosphere with in situ aircraft instruments, Geophys. Res. Lett., 31, L22107, doi:10.1029/2004GL020730, 2004.

Gettelman, A., Fetzer, E. J., Eldering, A., and Irion, F. W.: The global distribution of supersaturation in the upper troposphere from the Atmospheric Infrared Sounder, J. Climate, 19, 60896103, 2006.

Gierens, K., Kohlhepp, R., Spichtinger, P., and SchroedterHomscheidt, M.: Ice supersaturation as seen from TOVS, Atmos. Chem. Phys., 4, 539-547, 2004, http://www.atmos-chem-phys.net/4/539/2004/.

Gierens, K. and Spichtinger, P.: Comment on "The impact of temperature errors on perceived humidity supersaturation", edited by: Buehler, S. A. and Courcoux, N., Geophys. Res. Lett., 31, L02113, doi:10.1029/2003GL018695, 2004.

Haag, W., Kärcher, B., Ström, J., Minikin, A., Lohmann, U., Overlez, J., and Stohl, A.: Freezing thresholds and cirrus cloud formation mechanisms inferred from in situ measurements of relative humidity, Atmos. Chem. Phys., 3, 1791-1806, 2003, http://www.atmos-chem-phys.net/3/1791/2003/.

Hartmann, D. L., Holton, J. R., and Fu, Q.: The heat balance of the tropical tropopause, cirrus, and stratospheric dehydration, Geophys. Res. Lett., 28(10), 1969-1972, doi:10.1029/2000GL012833, 2001.

Heymsfield, A. J., Miloshevich, L. M., Twohy, C., Sachse, G., and Oltmans, S.: Upper-tropospheric relative humidity observations and implications for cirrus ice nucleation, Geophys. Res. Lett., 25, 1343-1346, 1998.

Heymsfield, A. J., Schmitt, C., Bansmer, A., van Zadelhoff, G.-J., McGill, M. J., Twohy, C., and Baumgardner, D.: Effective radius of ice cloud particle populations derived from aircraft probes, J. Atmos. Ocean. Tech., 23, 361-380, 2006.

Holton, J. R., Haynes, P. H., McIntyre, M. E., Douglass, A. R., Rood, R. B., and Pfister, L.: Stratosphere-troposphere exchange, Rev. Geophys., 33, 403-439, 1995.

Hong, G., Yang, P., Huang, H. -L., Ackerman, S. A., and Sokolik, I. N.: Simulation of high-spectral-resolution infrared signature of overlapping cirrus clouds and mineral dust, Geophys. Res. Lett., 33, L04805, doi:10.1029/2005GL024381, 2006.

Hong, G., Yang, P., Huang, H. L., Baum, B. A., Hu, Y. X., and Platnick, S.: The sensitivity of ice cloud optical and microphysical passive satellite retrievals to cloud geometrical thickness, IEEE Trans. Geosci. Remote. Sens., 45, 1315-1323, 2007.

Huang, H. L., Yang, P., Wei, H. L., Baum, B. A., Hu, Y. X., Antonelli, P., and Ackerman, S. A.: Inference of ice cloud properties from high spectral resolution infrared observations, IEEE Trans. Geosci. Remote. Sens., 42, 842-853, 2004.
Jensen, E. J., Pfister, L., Ackerman, A. S., Tabazadeh, A., and Toon, O. B.: A conceptual model of the dehydration of air due to freeze-drying by optically thin, laminar cirrus rising slowly across the tropical tropopause, J. Geophys. Res., 106, $17237-$ $17252,2001$.

Jensen, E. J., Smith, J. B., Pfister, L., et al.: Ice supersaturations exceeding $100 \%$ at the cold tropical tropopause: implications for cirrus formation and dehydration, Atmos. Chem. Phys., 5, 851862,2005 ,

http://www.atmos-chem-phys.net/5/851/2005/.

Kahn, B. H., Eldering, A., Clough, S. A., et al.: Near micronsized cirrus cloud particles in high-resolution infrared spectra: An orographic case study, Geophys. Res. Lett., 30(8), 1441, doi:10.1029/2003GL016909, 2003.

Kahn, B. H., Eldering, A., Ghil, M., Bordoni, S., and Clough, S. A.: Sensitivity analysis of cirrus cloud properties from highresolution infrared spectra, Part I: Methodology and synthetic cirrus, J. Climate, 17, 4856-4870, 2004.

Kahn, B. H., Liou, K.-N., Lee, S.-Y., et al.: Nighttime cirrus detection using Atmospheric Infrared Sounder window channels and total column water vapor, J. Geophys. Res., 110, D07203, doi:10.1029/2004JD005430, 2005.

Kahn, B. H., Eldering, A., Braverman, A. J., Fetzer, E. J., Jiang, J. H., Fishbein, E., and Wu, D. L.: Toward the characterization of upper tropospheric clouds using Atmospheric Infrared Sounder and Microwave Limb Sounder observations, J. Geophys. Res., 112, D05202, doi:10.1029/2006JD007336, 2007a.

Kahn, B. H., Fishbein, E., Nasiri, S. L., Eldering, A., Fetzer, E. J., Garay, M. J., and Lee, S.-Y.: The radiative consistency of Atmospheric Infrared Sounder and Moderate Resolution Imaging Spectroradiometer cloud retrievals, J. Geophys. Res., 112, D09201, doi:10.1029/2006JD007486, 2007b.

Kahn, B. H., Chahine, M. T., Stephens, G. L., Mace, G. G., Marchand, R. T., Wang, Z., Barnet, C. D., Eldering, A., Holz, R. E., Kuehn, R. E., and Vane, D. G.: Cloud type comparisons of AIRS, CloudSat, and CALIPSO cloud height and amount, Atmos. Chem. Phys., 8, 1231-1248, 2008, http://www.atmos-chem-phys.net/8/1231/2008/.

Kärcher, B. and Strom, J.: The roles of dynamical variability and aerosols in cirrus cloud formation, Atmos. Chem. Phys., 3, 823838, 2003, http://www.atmos-chem-phys.net/3/823/2003/.

Kärcher, B.: Cirrus clouds in the tropical tropopause layer: Role of heterogeneous ice nuclei, Geophys. Res. Lett., 31, L12101, doi:10.1029/2004GL019774, 2004.

Kay, J. E.: Physical controls on cirrus cloud inhomogeneity, Ph.D thesis, University of Washington, 157 pp., 2006.

Khvorostyanov, V. I., Morrison, H., Curry, J. A., Baumgardner, D., and Lawson, P.: High supersaturation and modes of ice nucleation in thin tropopause cirrus: Simulation of the 13 July 2002 cirrus regional study of tropical anvils and cirrus layers case, J. Geophys. Res., 111, D02201, doi:10.1029/2004JD005235, 2006.

Koop, T., Luo, B., Tsias, A., and Peter, T.: Water activity as the determinant for homogeneous ice nucleation in aqueous solutions, Nature, 406, 611-614, 2000.

L'Ecuyer, T. S., Gabriel, P., Leesman, K., Cooper, S. J., and Stephens, G. L.: Objective assessment of the information content of visible and infrared radiance measurements for cloud microphysical property retrievals over the global oceans. Part I: Liquid 
clouds, J. Appl. Meteor. Climatol., 45, 20-41, 2006.

Lilly, D. K.: Cirrus outflow dynamics, J. Atmos. Sci., 45, 15941605, 1988.

Liou, K. N.: Influence of cirrus clouds on weather and climate processes - A global perspective, Mon. Weather Rev., 114, 11671199, 1986.

Lohmann, U. and Kärcher, B.: First interactive simulations of cirrus clouds formed by homogeneous freezing in the ECHAM general circulation model, J. Geophys. Res., 107(D10), 4105, doi:10.1029/2001JD000767, 2002.

Lynch, D. K., Sassen, K., Starr, D. O., and Stephens, G. L. (Eds.): Cirrus, Oxford Press, New York, 449-455, 2002.

Mace, G. G., Deng, M., Soden, B., and Zipser, E.: Association of tropical cirrus in the $10-15 \mathrm{~km}$ layer with deep convective sources: An observational study combining millimeter radar data and satellite-derived trajectories, J. Atmos. Sci., 63, 480-503, 2006.

Magee, N., Moyle, A. M., and Lamb, D.: Experimental determination of the deposition coefficient of small cirrus-like ice crystals near $-50^{\circ} \mathrm{C}$, Geophys. Res. Lett., 33, L17813, doi:10.1029/2006GL026665, 2006.

Massie, S., Gettelman, A., Randel, W., and Baumgardner, D.: Distribution of tropical cirrus in relation to convection, J. Geophys. Res., 107, 4591, doi:10.1029/2001JD001293, 2002.

McFarquhar, G. M., Macke, A., Iaquinta, J., and Aulenbach, S. M.: Use of observed ice crystal sizes and shapes to calculate meanscattering properties and multispectral radiances: CEPEX April 4, 1993, case study, J. Geophys. Res., 104, 31 763-31 779, 1999.

McFarquhar, G. M., Heymsfield, A. J., Spinhirne, J., and Hart, B.: Thin and subvisual tropopause tropical cirrus: Observations and radiative impacts, J. Atmos. Sci., 57, 1841-1853, 2000.

McMillin, L. M., Crone, L. J., Goldberg, M. D., and Kleespies, T. J.: Atmospheric transmittance of an absorbing gas 4: OPTRAN: a computationally fast and accurate transmittance model for absorbing gases with variable mixing ratios at variable viewing angles, Appl. Opt., 34, 6269-6274, 1995.

Meyer, K., Yang, P., and Gao, B.-C.: Tropical ice cloud optical depth, ice water path, and frequency fields inferred from the MODIS level-3 data, Atmos. Res., 85, 171-182, 2007.

Miloshevich, L. M., Vömel, H., Whiteman, D. N., Lesht, B. M., Schmidlin, F. J., and Russo, F.: Absolute accuracy of water vapor measurements from six operational radiosonde types launched during AWEX-G and implications for AIRS validation, J. Geophys. Res., 111, D09S10, doi:10.1029/2005JD006083, 2006.

Minnis, P., Ayers, J. K., Palikonda, R., and Phan, D.: Contrails, cirrus trends, and climate, J. Climate, 17, 1671-1685, 2004.

Mote, P. W. and Frey, R.: Variability of clouds and water vapor in low latitudes: View from the Moderate Resolution Imaging Spectroradiometer (MODIS), J. Geophys. Res., 111, D16101, doi:10.1029/2005JD006791, 2006.

Ovarlez, J., Gayet, J.-F., Gierens, K., Ström, J., Ovarlez, H., Auriol, F., Busen, R., and Schumann, U.: Water vapour measurements inside cirrus clouds in Northern and Southern hemispheres during INCA, Geophys. Res. Lett., 29, 1813, doi:10.1029/2001GL014440, 2002.

Peter, T., Luo, B. P., Wirth, M., et al.: Ultrathin tropical tropopause clouds (UTTCs): I. Cloud morphology and occurrence, Atmos. Chem. Phys., 3, 1083-1091, 2003, http://www.atmos-chem-phys.net/3/1083/2003/.
Peter, T., Marcolli, C., Spichtinger, P., Corti, T., Baker, M. B., and Koop, T.: When dry air is too humid, Science, 314, 1399-1402, 2006.

Popp, P. J., Gao, R. S., Marcy, T. P., et al.: Nitric acid uptake on subtropical cirrus cloud particles, J. Geophys. Res., 109, D06302, doi:10.1029/2003JD004255, 2004.

Prabhakara, C., Fraser, R. S., Dalu, G., Wu, M. L. C., Curran, R. J., and Styles, T.: Thin cirrus clouds - Seasonal distribution over oceans deduced from NIMBUS-4 IRIS, J. Appl. Meteor., 27, 379-399, 1988.

Ramanathan, V. and Collins, W.: Thermodynamic regulation of ocean warming by cirrus clouds deduced from observations of the 1987 El Nino, Nature, 351, 27-32, 1991.

Read, W. G., Lambert, A., Bacmeister, J., et al.: Aura Microwave Limb Sounder upper tropospheric and lower stratospheric $\mathrm{H}_{2} \mathrm{O}$ and relative humidity with respect to ice validation, J. Geophys. Res., 112, D24S35, doi:10.1029/2007JD008752, 2007.

Remer, L. A., Kaufman, Y. J., Tanré, D., et al.: The MODIS aerosol algorithm, products, and validation, J. Atmos. Sci., 62, 947-973, 2005.

Sandor, B. J., Jensen, E. J., Stone, E. M., Read, W. G., Waters, J. W., and Mergenthaler, J. L.: Upper tropospheric humidity and thin cirrus, Geophys. Res. Lett., 27, 2645-2648, 2000.

Soden, B. J., Jackson, D. L., Ramaswamy, V., Schwarzkopf, M. D., and Huang, X. L.: The radiative signature of upper tropospheric moistening, Science, 310, 841-844, 2005.

Spichtinger, P., Gierens, K., Smit, H. G. J., Ovarlez, J., and Gayet, J.-F.: On the distribution of relative humidity in cirrus clouds, Atmos. Chem. Phys., 4, 639-647, 2004, http://www.atmos-chem-phys.net/4/639/2004/.

Stephens, G. L., Vane, D. G., Boain, R. J., et al.: The CloudSat mission and the A-train, B. Am. Meteorol. Soc., 83, 1771-1790, 2002.

Ström, J., Seifert, M., Kärcher, B., et al.: Cirrus cloud occurrence as function of ambient relative humidity: a comparison of observations obtained during the INCA experiment, Atmos. Chem. Phys., 3, 1807-1816, 2003, http://www.atmos-chem-phys.net/3/1807/2003/.

Stubenrauch, C. J., Eddounia, F., and Rädel, G.: Correlations between microphysical properties of large-scale semi-transparent cirrus and the state of the atmosphere, Atmos. Res., 72, 403-423, 2004.

Tobin, D. C., Revercomb, H. E., Knuteson, R. O., et al.: Atmospheric Radiation Measurement site atmospheric state best estimates for Atmospheric Infrared Sounder temperature and water vapor retrieval validation, J. Geophys. Res., 111, D09S14, doi:10.1029/2005JD006103, 2006.

Tobin, D. C., Moy, L., Knuteson, R., Revercomb, H., Best, F., and Taylor, J.: Update on aircraft validation efforts; $T / q$ retrieval validation using ARM data, Atmospheric Infrared Sounder Science Team Meeting, http://www-airs.jpl.nasa.gov/Science/ResearcherResources/ MeetingArchives/TeamMeeting20070327/, Pasadena, CA, 27-30 March, 2007.

van Zadelhoff, G.-J., Donovan, D. P., Klein Baltink, H., and Boers, R.: Comparing ice cloud microphysical properties using CloudNET and Atmospheric Radiation Measurement Program data, J. Geophys. Res., 109, D24214, doi:10.1029/2004JD004967, 2004. Wendisch, M., Yang, P., and Pilewskie, P.: Effects of 
ice crystal habit on thermal infrared radiative properties and forcing of cirrus, J. Geophys. Res., 112, D08201, doi:10.1029/2006JD007899, 2007.

Wentz, F. J., Gentemann, C., Smith, D., and Chelton, D.: Satellite measurements of sea surface temperature through clouds, Science, 288, 847-850, 2000.

Winker, D. M. and Trepte, C. R.: Laminar cirrus observed near the tropical tropopause by LITE, Geophys. Res. Lett., 25, 33513354, 1998.

Winker, D. M., Hunt, B., and McGill, M.: Initial performance assessment of CALIOP, Geophys. Res. Lett., 34, L18805, doi:10.1029/2007GL029938, 2007.
Wylie, D. P. and Menzel, W. P.: Eight years of high cloud statistics using HIRS, J. Climate, 12, 170-184, 1999.

Yang, P., Wei, H.-L., Baum, B. A., et al: The spectral signature of mixed-phase clouds composed of non-spherical ice crystals and spherical liquid droplets in the terrestrial window region, J. Quant. Spectrosc. Radiat. Transfer, 79-80, 1171-1188, 2003.

Yue, Q., Liou, K. N., Ou, S. C., Kahn, B. H., Yang, P., and Mace, G. G.: Interpretation of AIRS data in thin cirrus atmospheres based on a fast radiative transfer model, J. Atmos. Sci., 64, 3827-3842, 2007. 